\title{
أثثر الحرب على بعض المتغيَّات الاقتصادية الكلية في الاقتصاد اليمني \\ دراسة تحليلية وصفية للفترة (2015-2017)
}

The Impact of War on Some Macroeconomic Variables in The Yemeni Economy

A Descriptive Analytical Study for the Period (2015-2017)

\section{د عبله مدهش صالح الشجري(1)}

\section{Dr.Abdo Modhish Saleh Al-shigri}




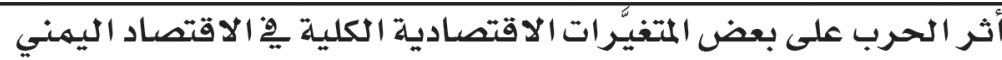

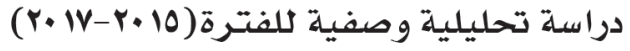

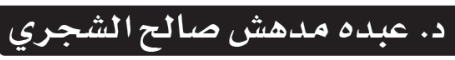

\section{ملخص الدراسة:}

هدفت الدراسة التعرف إلى أثر الحـرب على بعض المتغيَّرات الاقتصاديـة الكلية، وهي: الناتج المحلي الإجمالي، الموازنة العامـة، سعر الصرف، الميزان التجاري، المديونيـة.

وتوصَّلت الدراسة إلى النتائج التالية: انكمش الناتج المحلي الإجمالي بمعدل تراكمي خلال السنوات الثلاث الأولى للحرب وصل 55\%. بلغ عجز الموازنة العامة بعد الحرب خلال الفترة 2015-2017 كمتوسط الجط

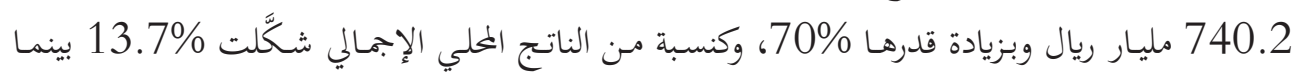
كانت قبل الحرب 3\%.6. بلغ العجز في الميزان التجاري كمتوسط للفترة( 2015-2017 ) 1330 مليـار ريال، وكنسبة من الناتج المحلي الإجمالي 24.8\%. انخفضت قيمـة العملة بالمتوسط خهلال الفترة 2015-2018، بمعدل سنوي 66\%. ارتفعت المديونية بعد الحرب بشكل حاد، وشكَّلت كنسبة من الناتج المحلي الإجمالي بلغت 128\% كمتوسط للفترة(2015-2017) . كلمات مفتاحية: اقتصاد الحرب-الناتج العحلي الإجمالي-الموازنة العامة-العجز في الميزان التجاريسعر الصرف

المجلد ( 2 ) - العدد (21 ) ديسمبر 2021م 


\section{Abstract}

The study aimed at identifying the impact of the war on some macroeconomic variables, namely: gross domestic product, public budget, exchange rate, trade balance, and indebtedness. The study concluded that gross domestic product shrank at a cumulative rate of 55\% during the first three years of the war. After the war and during the period 20152017-, the public budget deficit amounted to an average of 740.2 billion riyals, with an increase of $70 \%$, and accounted for $13.7 \%$ of the GDP, compared to $6.3 \%$ before the war. The average deficit in the trade balance for the period 20152017- amounted to 1330 billion riyals, and as $24.8 \%$ of the GDP. The currency's value, on average, decreased at an annual rate of 66\% during the period 20152018-. The debt rose after the war, and constituted 128\% of the GDP as an average for the period 20152017-.

Keywords: war economy, GDP, gross, general budget, trade balance deficit, exchange rate. 


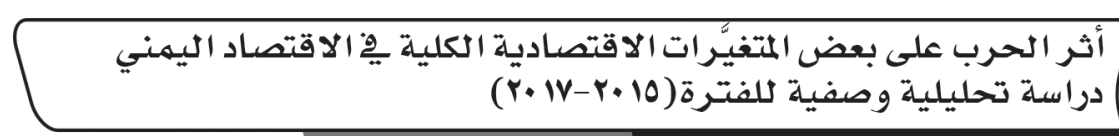

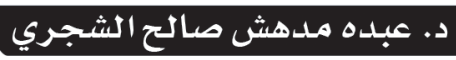

المقدمة:

طالت مدة الحرب في اليمن وانعكست تبعاةًا على الاقتصاد والمجتمع، وتزايدات مؤخرًا مؤشرات تفاقُم

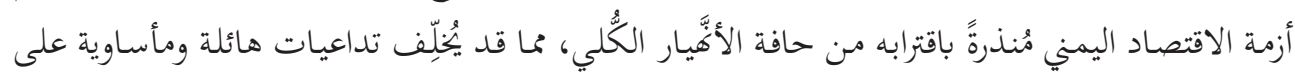

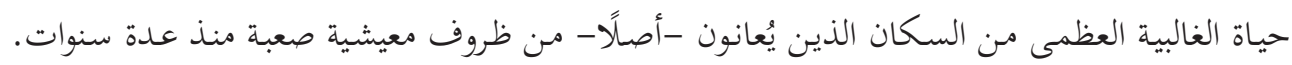
يهدف هذا البحث إلى دراسة تأثير الحرب على بعض المئ المتغيَّات الاقتصادية الكلية التي تنعكس على على أداء

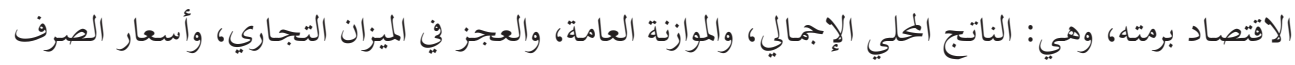

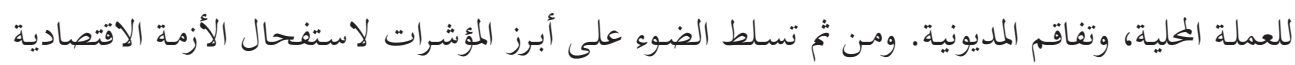

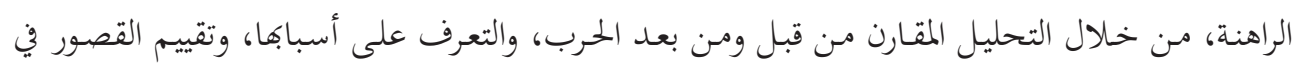

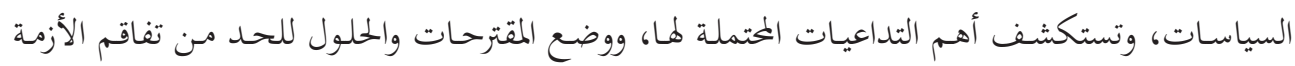
الاقتصادية في ظل اقتصاد الحرب.

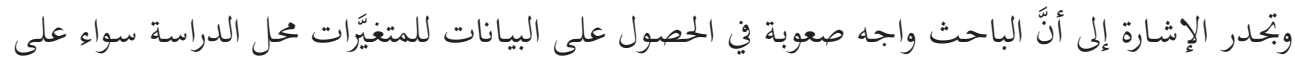

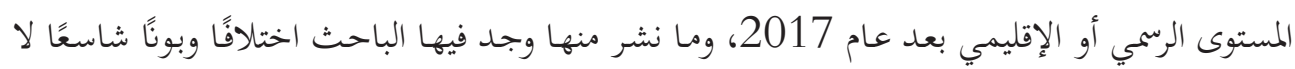

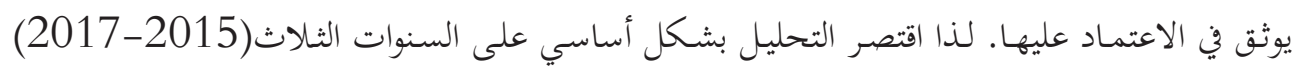
بعد الحرب.

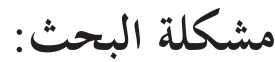

للحرب آثار على المتغيَّرات الاقتصادية الكلية وعلى المستوى المعيشي للمجتمع، هذه الأثار قـد تنذر

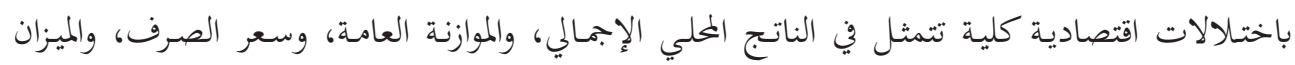

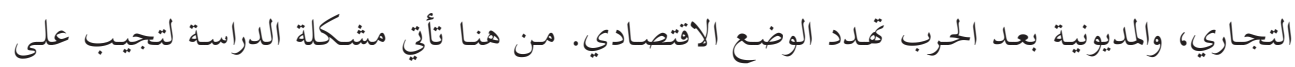

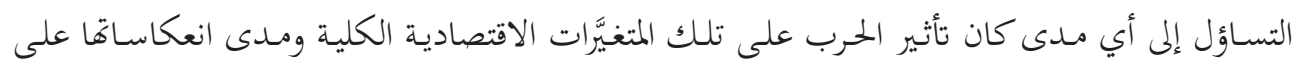
فمديد الوضع الاقتصادي والمستوى المعيشي للسكان.

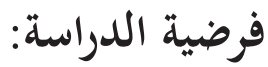

تنطلق الدراسة من فرضية أساسية، وهي للحرب تأثير سلبي على المتغيَّات الاقتصادية الكلية. ومنها تتفرع الفرضيات التالية:

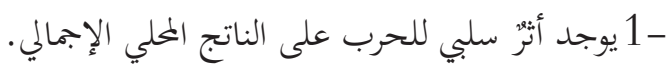

المجلد ( 2 ) - العدد ( 2 ) ديسمبر 2021م 
أثر الحرب على بعض المتغيَّرات الاقتصادية الكلية بِّاِ الاقتصاد اليهني

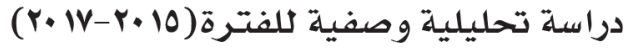

\section{د. عبلده مدهش صالت الشجري}

$$
\begin{aligned}
& \text {-2 يوجد أثر سلبي للحرب على وضع الموازنة العامة. } \\
& \text {-3 يوجد أثر سلبي للحرب على وضع الميزان التجاري. } \\
& \text {-4 يوجد أثر سلبي للحرب على قيمة العملة المحلية. } \\
& \text {-5 يوجد أثر سلبي للحرب على الدين العام المحلي والخارجي. }
\end{aligned}
$$

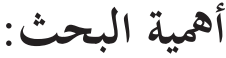

تأتي أهمية الدراسة كوها تعد من الدراسات الأُول التي خاضت في تحليل الأثار الاقتصادية للحرب على التي

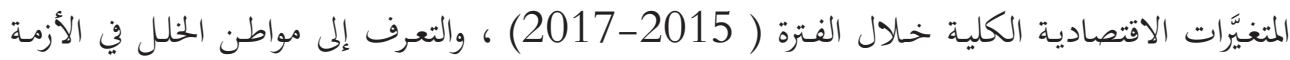

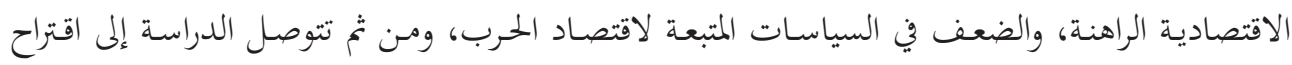

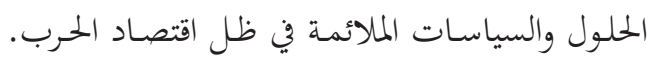

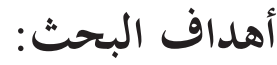

1-همف الدراسة التعرف إلى تحليل الإطار النظري لاقتصاد الحرب.

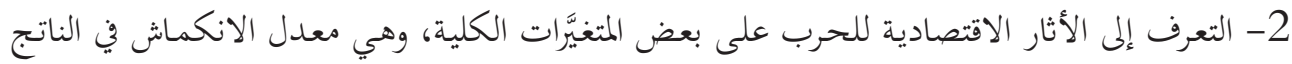

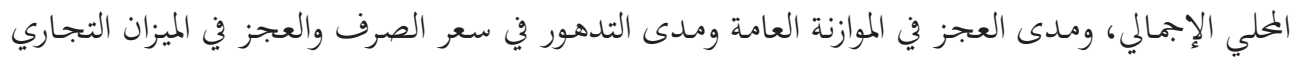
وتفاقم المديونية. 3-التعرف إلى مدى اتباع الحكومة السياسات الاقتصادية الملائمة للتكيف مع اقتصاد الحرب. منهجية الدراسة:

ولغرض تحقيق هدف الدراسة وإثبات فرضياته، اتبع الباحث المنهج الوصفي من خلال التحليل المقارن

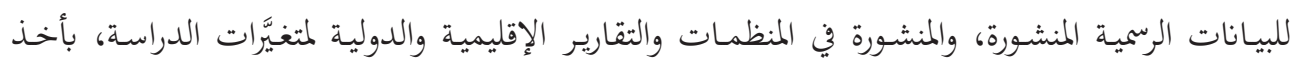

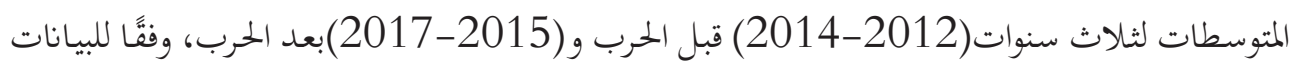

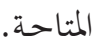

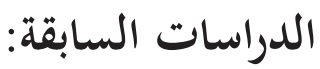

-1 دراسة ( . Ehmer) وهدفت إلى دراسة أثر الحرب الأهلية في سيري ليون على الاقتصاد الكلي

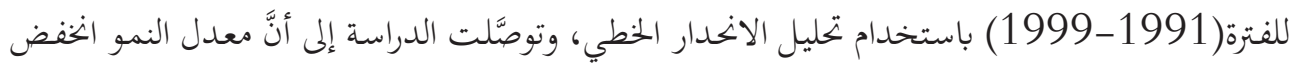

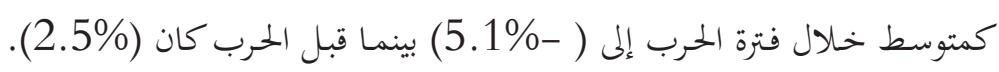




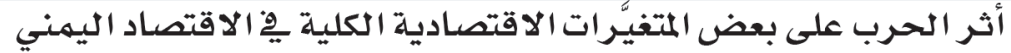

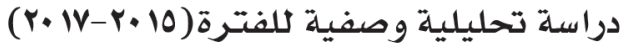

\section{د. عبده مداهش صالح الشجري}

-2 دراسة ( 2012.20rneels and Verpoorten.

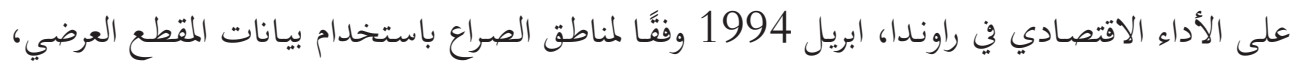

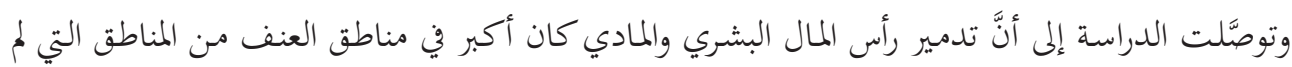
يشملها العنف.

-3 دراسة ( Peace Research Institution Oslo (PRIO).2012) وهدفت إلى تحليل أثر الصراع المسلح على أهداف التنمية الالفية (MDGs) للأمم المتحدة، باستخدام البيانات لخمس ولند

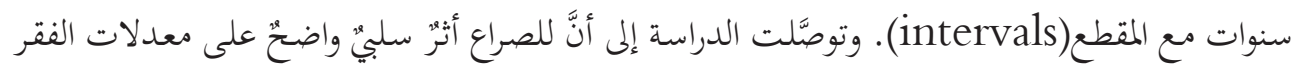

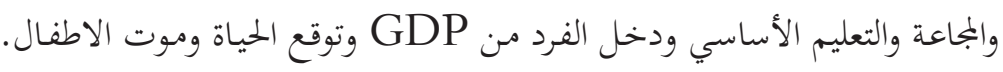

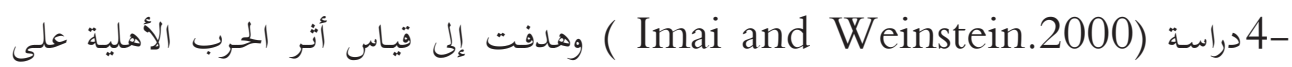

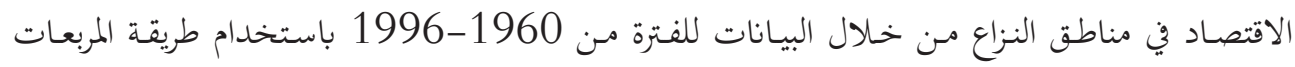

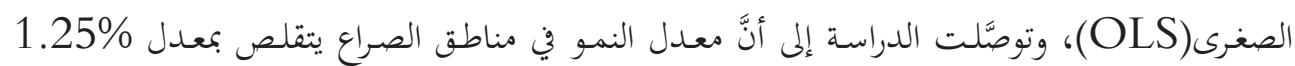

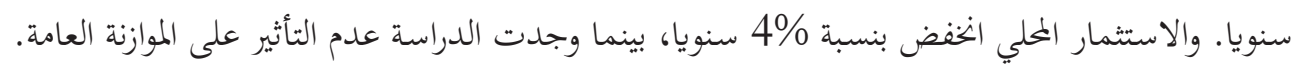

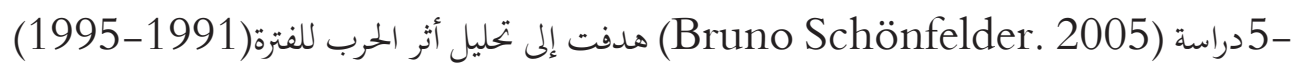

على الاقتصاد الكرواتي، وتوصَّلت إلى النتائج التالية: - انخفض تسويق منتجات قطاعي الإنتاج والخدمات إلى النصف في بداية التسعينات.

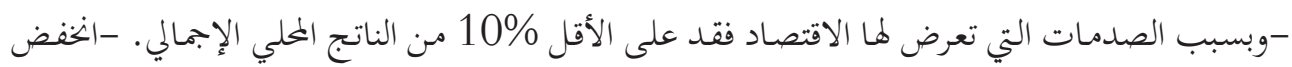

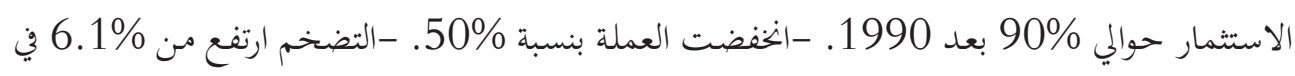

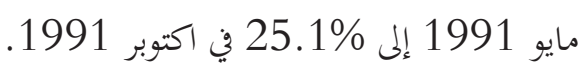

\section{خطة الدراسة: - مايو}

بغية تحقيق أهداف الدراسة اشتملت الخطة على أربعة مباحث، وهي على النحو التالي:

$$
\text { م2 م- مد الإطار المفاهيمي للدراسة. }
$$

م-تحليل تأثير الحرب على المتغيَّرات الاقتصادية الكلية التالية:

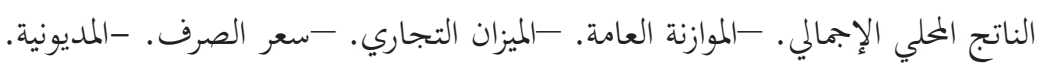
م-4 - الاستناجات والتوصيات.

المجلد ( 2 ) - العدد ( 2 (2021 ) ديسمبر 2021م - (20دمد 
المبحث الأول الإطار المفاهيمي للدراسة:

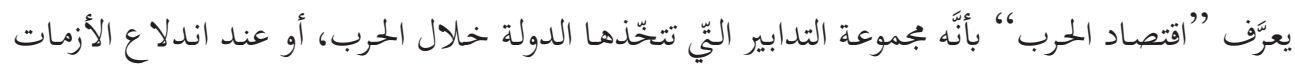

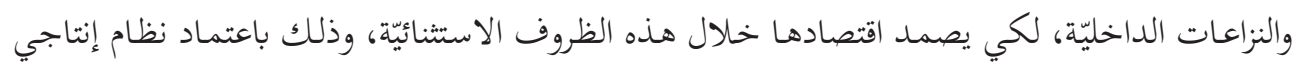

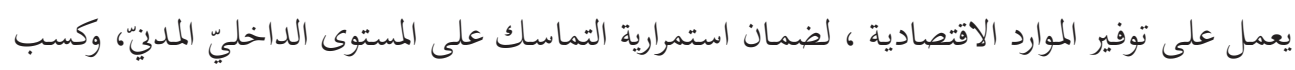

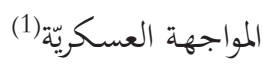

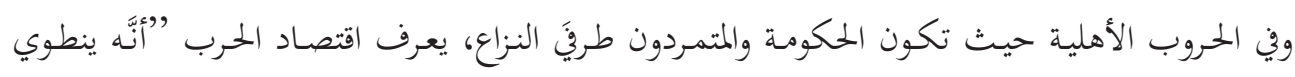

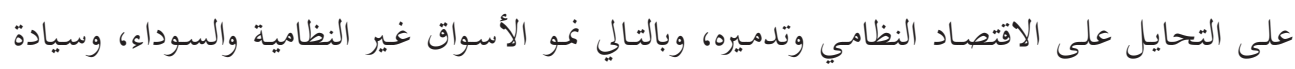

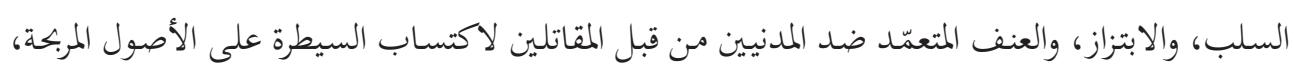
واستغلال اليد العاملة) (2) ويفهم مـن خلال التعريفات السابقة، أنَّ اقتصاد الحرب ينطوي على مفهومين، يتصل الأول بالدولة التي

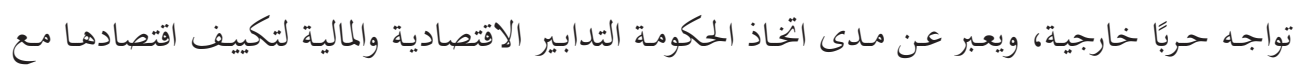

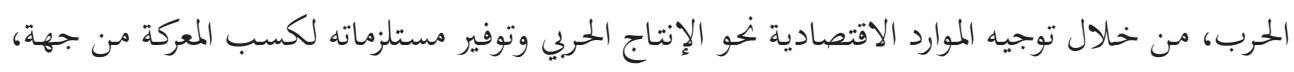

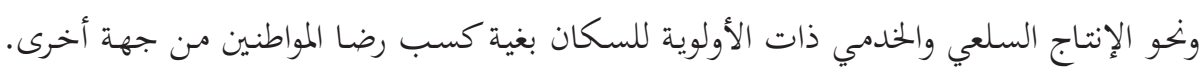

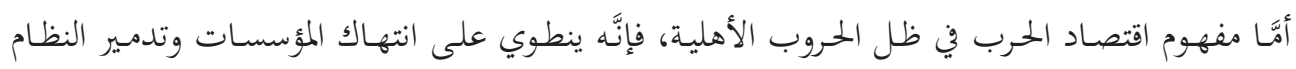

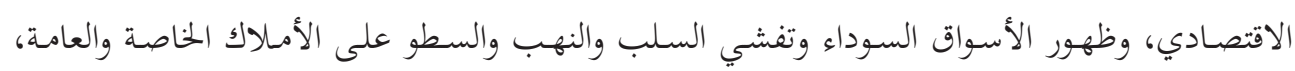

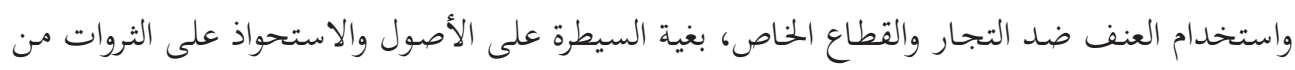

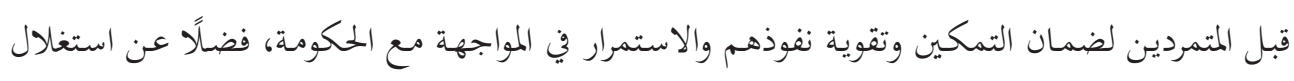

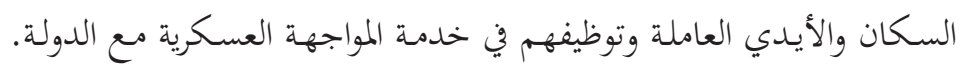

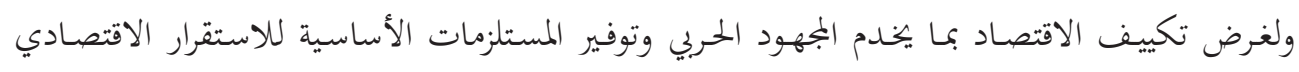

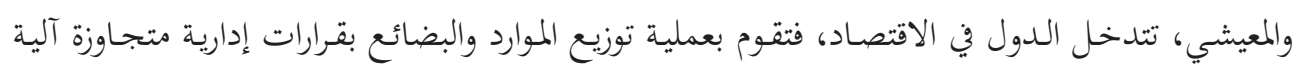

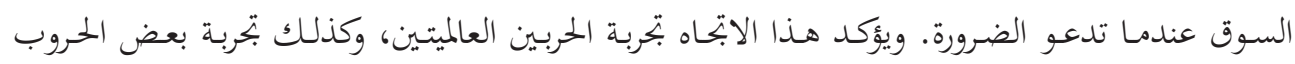

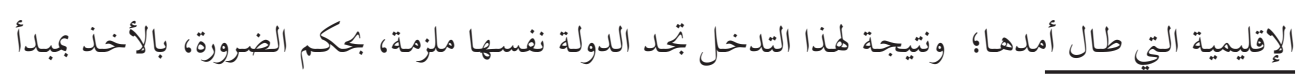

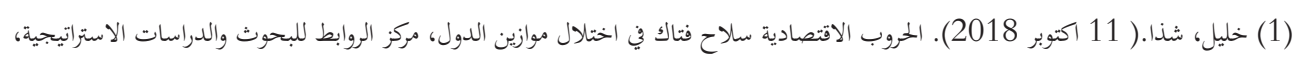
https://rawabetcenter.com/archives/75567 "(2014) الحميري، محمد اممد، (23يناير، 2018)، اقتصاد الحرب في اليمن :التدابير الاقتصادية لجماعة أنصّار الله "الحوثيين" بعد سبتمبر

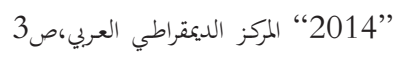
51726=p?/de.democraticac//:https

المجلد ( 2 ) - العدد (2021 (2 ) ديسمبر 2021م 


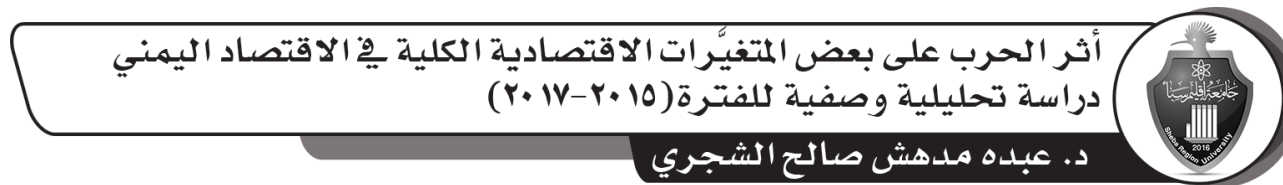

التوجيه الإداري للموارد والسلع وإخضاع الإنتاج والاستهلاك المدنيين للأغراض الحربية، ويف العادة تقوم

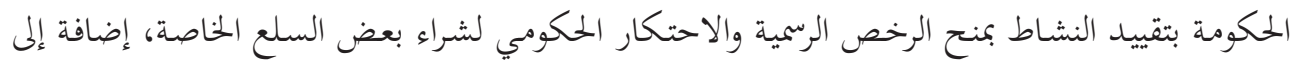

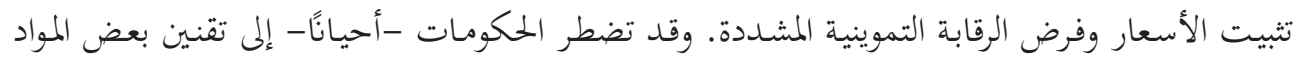

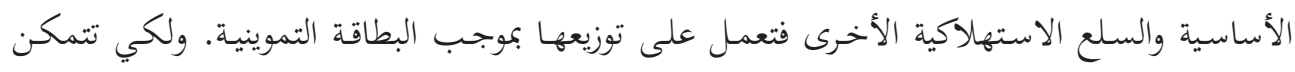

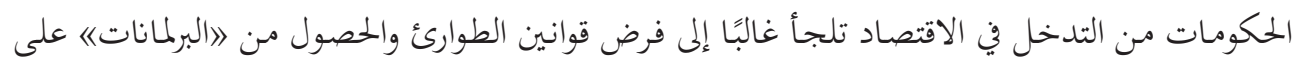

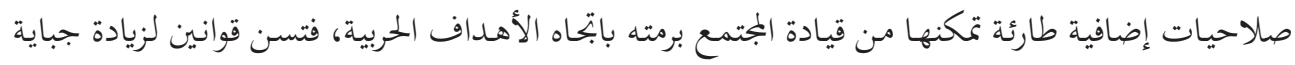

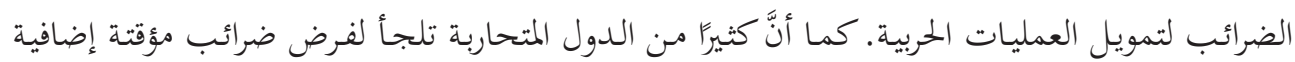

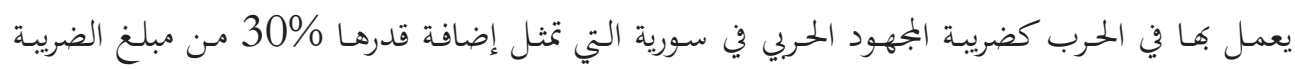

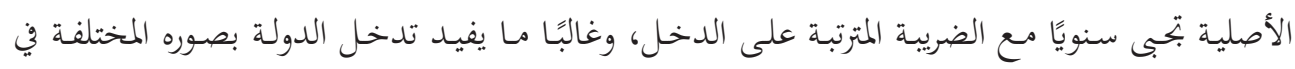

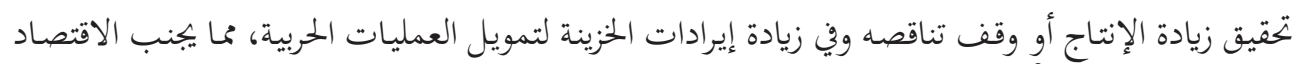
الوقوع في التضخم مئم ومن الشواهد للسياسات المتبعة في ابتحاه تكييف الاقتصاد لخدمة الحرب ما اتخذه رئيس الوزراء المصري في

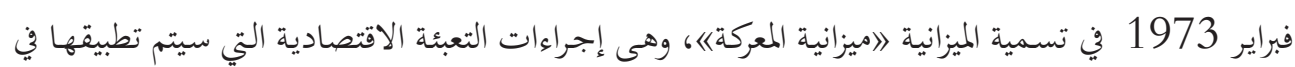

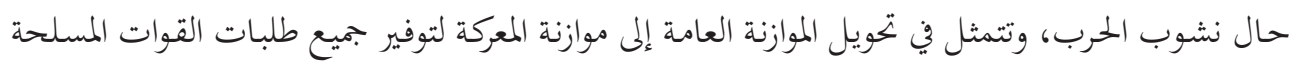

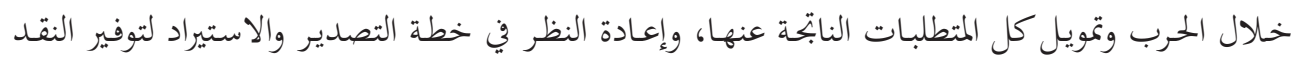

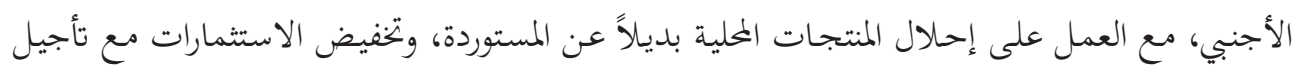

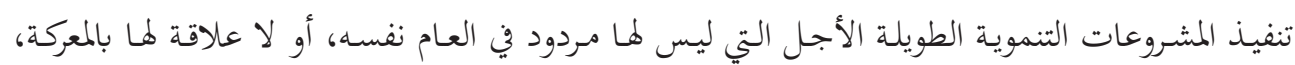
كذلك تخفيض في أنَّاع الإنفاق المختلفة بالمصالح الحكومية والقطاع العام( (4).

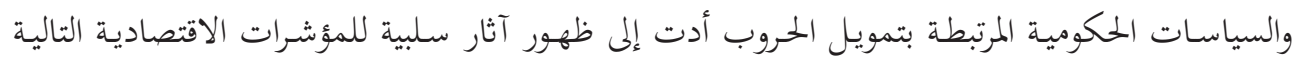

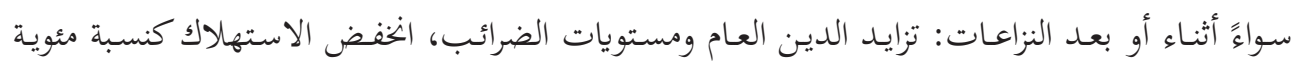

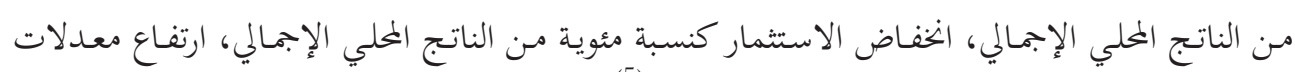

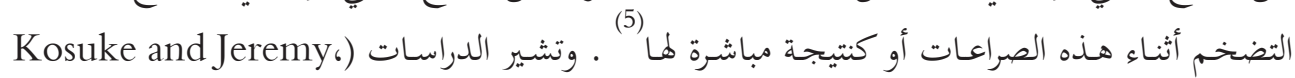

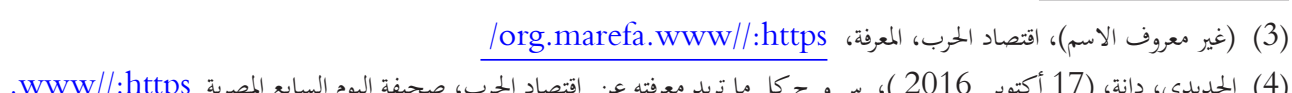

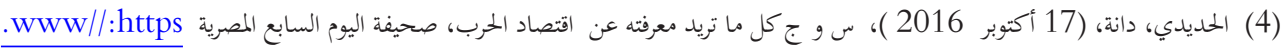
2926016//17/10/2016/story/com.youm7 Institute for Economics \& Peace (IEP)، ECONOMIC CONSEQUENCES OF WAR (5) on the U.S. ECONOMY، New York. P. 5 ديسمبر 2021م 


\section{د. عبلده مداهش صالح الشجري}

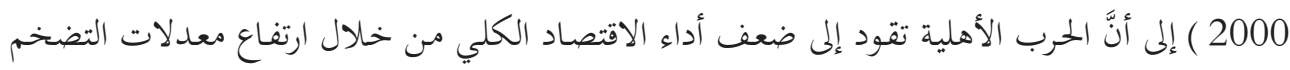

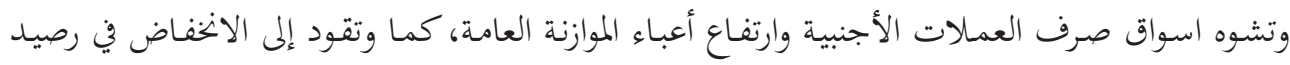

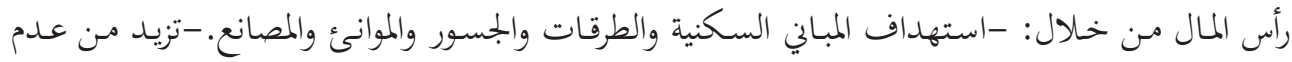
اليقين في البيئة الاقتصادية وتقود إلى تخفيض حجم الاستثمار الخاص ونقل الأصول السائلة إلى خارج

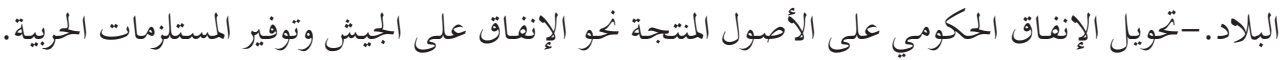

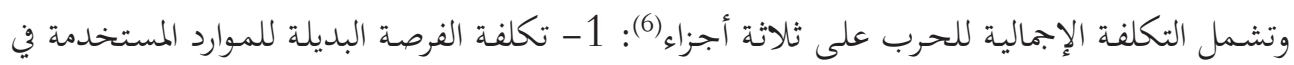

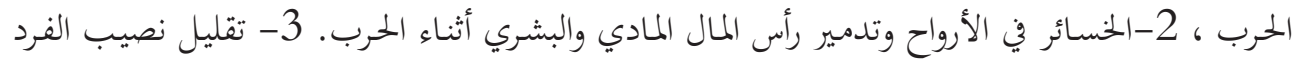

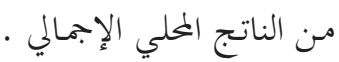

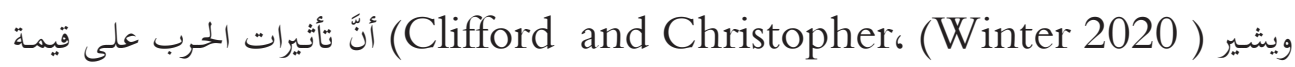
العملة والديون تتعقد بفعل احتمالات التضخم والتخلي عن الدين (7).

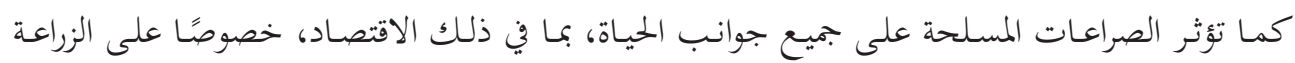

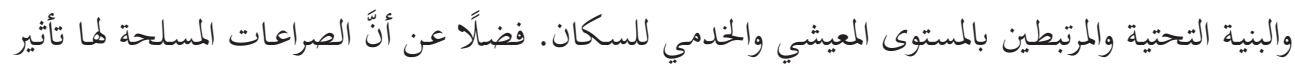

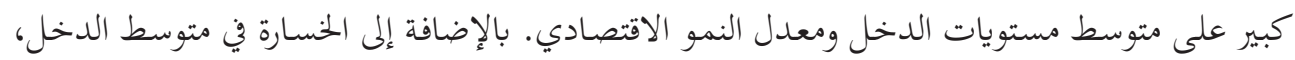

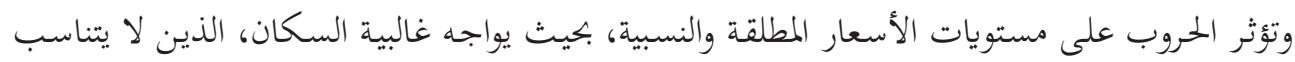
دخلهم مع التضخم، صعوبات متزايدة في تلبية احتياجاهم الأساسية(8).

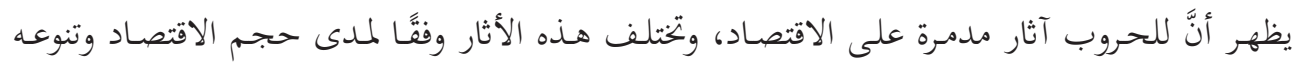

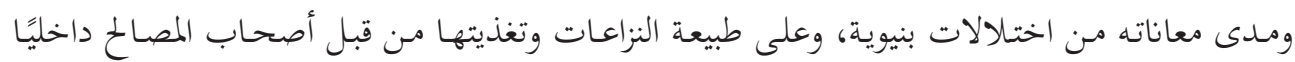

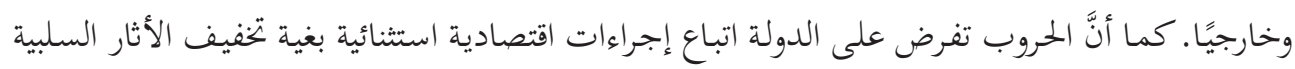
على الاقتصاد والانسان وبما يخدم مجهودها الحسا الحربي.

Clifford F. Thies and Christopher F. Baum .(winter 2020)، The Effect of War on Eco- (6) nomic Growth، Cato Journal، Vol. 40، No. 1. Cato Institute. P. 204 DOI:10.36009/CJ40.1.10 Clifford F. Thies and Christopher F. Baum .(winter 2020)، The Effect of War on Economic (7)

Growth، Cato Journal، Vol. 40، No. 1. Cato Institute. P، 205 Plumper and Eric Neumayer، (Summer 2006) ، the Unequal Burden of War: The Effect (8) of Armed Conflict on the Gender Gap in Life Expectancy، International Organization 60، pp. 


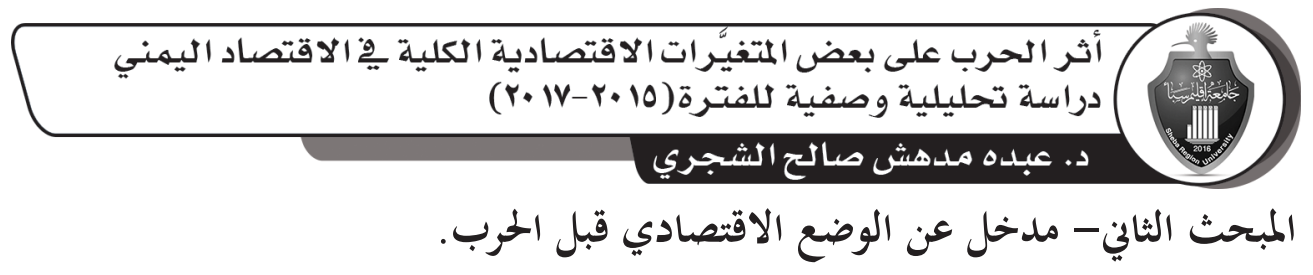

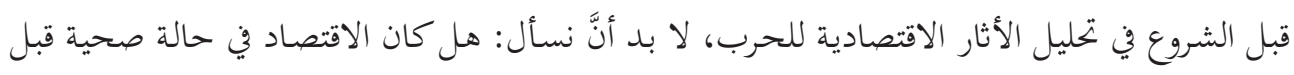

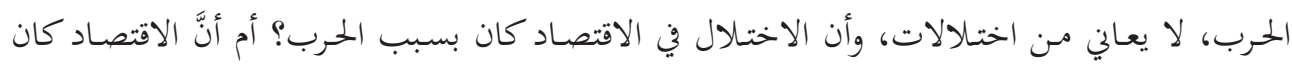

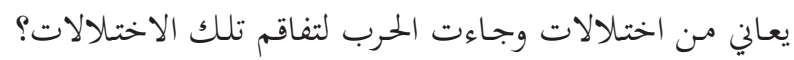

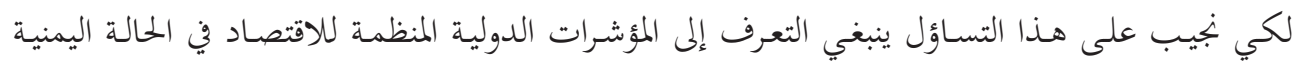

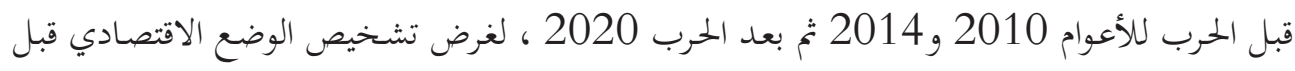

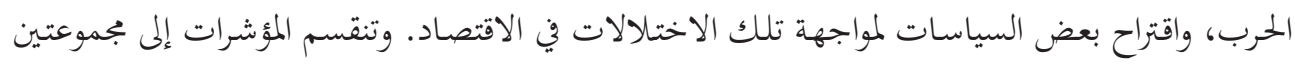

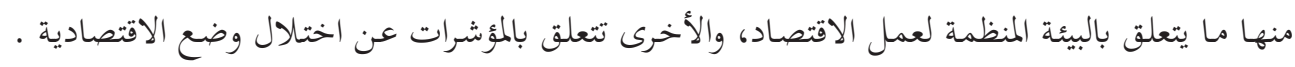

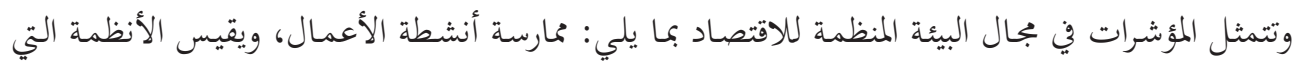

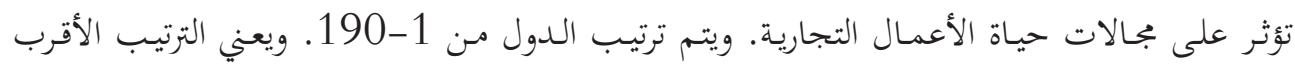

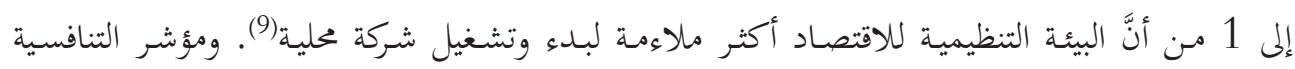

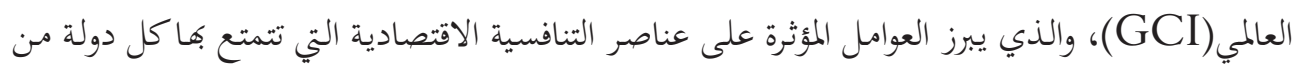

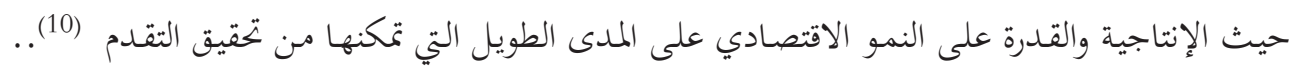

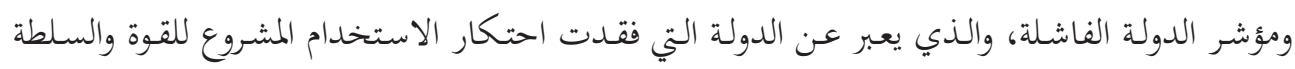

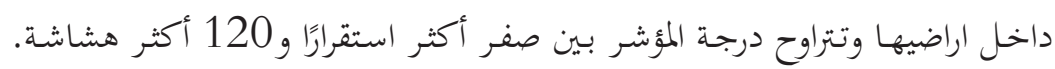

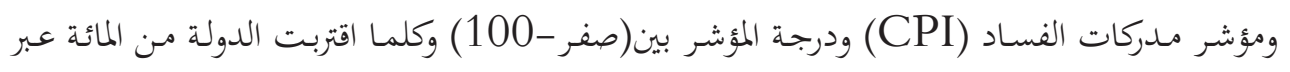

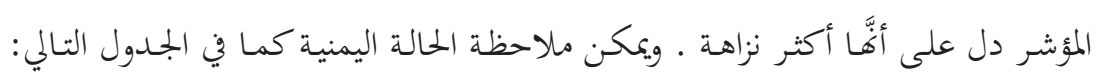

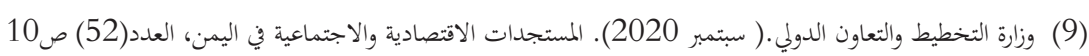

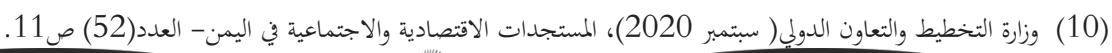

المجلد ( 2 ) - العدد (2021 (2) مبر ) ديسمبر 2021م

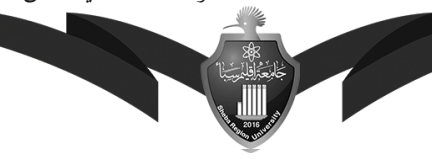


(7) د. عبلاه مدهش صالت الشجري

جدول رقم(1) يوضح المؤشرات الاقتصادية المنظمة لعمل بيئة الاقتصاد في اليمن

\begin{tabular}{|c|c|c|c|c|c|c|}
\hline \multicolumn{2}{|c|}{$r \cdot r \cdot$} & \multicolumn{2}{|c|}{$r+1 \varepsilon$} & \multicolumn{2}{|c|}{$r+1}$. & السنوات \\
\hline الترتيب & قيمة & الترتيب & قيمة & الترتيب & قيمة المؤشر & \\
\hline 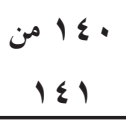 & 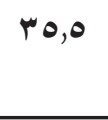 & ع ا من ^ع ا & & & & التنافسية العالمي \\
\hline مشاشة الأكثر & $11 r, \varepsilon$ & $\wedge$ & $1 \cdot 0, \varepsilon$ & 10 & $1 \cdots$ & الدولة الفاشلة \\
\hline 187 & 10 & 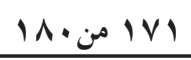 & 19 & $1 \leq 7$ & $r r$ & مدركات الفساد \\
\hline $\begin{array}{c}\text { I AV } \\
19 .\end{array}$ & & س & & 99 & & نشاط الأعمال \\
\hline
\end{tabular}

الجـدول مـن عمل الباحثث بالاعتمـاد على تقارير للشفافية العالميـة والمنتـى الاقتصـادي العالمي والبنـك الدولي. يلاحظ مـن الجمدول رقم (1) أنَّ البيئة المنظمة لعمل الاقتصاد قبل الحرب كانت غير مواتيـة وتفاقمت بشكل أكبر بعد الحرب، فمؤشر التنافسية لعام 2014، يشير إلى ترتيب اليمن في ذيل قائمة الدول برقم (145) وتسبق فقط ثلاث دول، وتفاقم ذلك المؤشر لتصبح في عام (2020) قبـل دولة واحسدة. أمَّا مؤشر الدولة الفاشلة فيلاحظ أنَّ اليمن تقع ضمن مؤشر الدول الفاشلة (أقلهّ عشرين دولة)، فترتيبها في عامي 2010، 2014 كان رقم (15، 8). وتفاقم ذلك بعد الحرب لتشكل الدولة الأولى في الهشاشة. ومؤشر مـدركات الفساد واقع أدنى مـن 25 (ضمن الدول الفاسدة)، فيلاحظ في عامي 2010، 2014 كان (22، 19) على التوالي، وتفاقفم ليصل بعد الحرب عـام 2020 إلى (15) ، وبترتيـب ضمن ذيل قائمة الدول العالمية. ومؤشر نشاط الأعمال على الرغم من أنَّه لم يكن متفاقما بشكل حاد

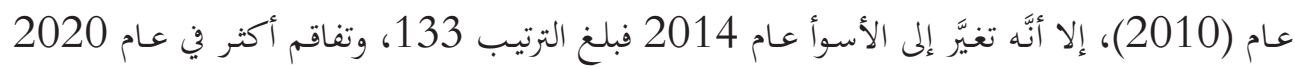
ليصبح الترتيب (187) مـن بين 190 دولة. والمؤشرات الاقتصادية التي تتصل باختلال الوضع الاقتصـادي تتمثل في انخفـاض حساد في الإيرادات الضريبية التي شكَّلت أدنى مـ 9\% 9 مـن الناتج المحلي الإجمالي مقارنـة بالمعدل للدول النامية المقـدر 


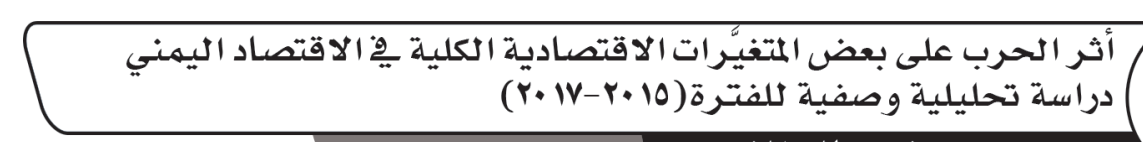

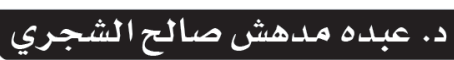

17.1\% ذات الاقتصادات القريبة مـن الاقتصاد اليمني (11). ومتوسط مساهمة النفقات الجارية كنسبة من النفقات العامة شكَّت $180 \%$ للفترة (2006-2010) ومتوسط الواردات الإدات كنسبة من الناتج المحلي

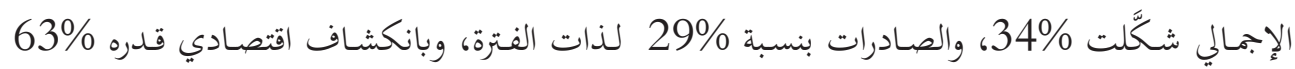

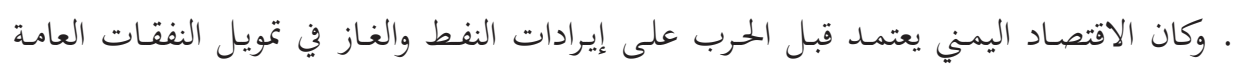
وتحقيق التوازن الخارجي في الحصول على العملات الصعبة لتمويل الاستيرادات، وتحقيق التوازن الداخلي

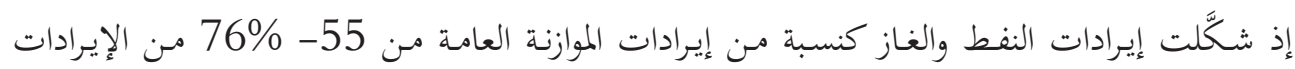

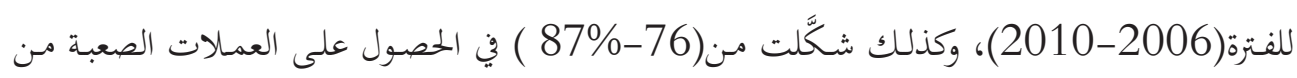

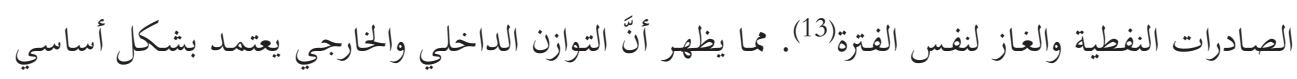

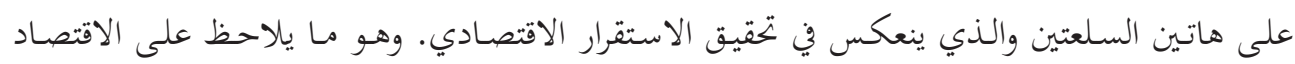

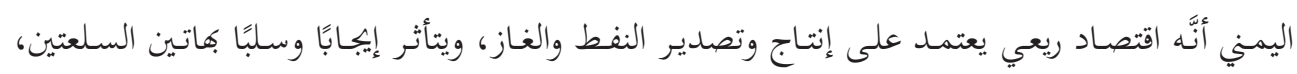

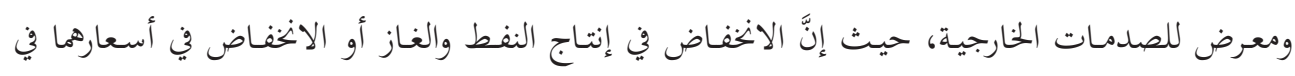

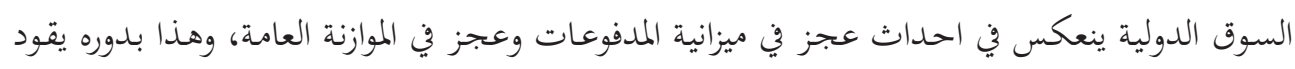

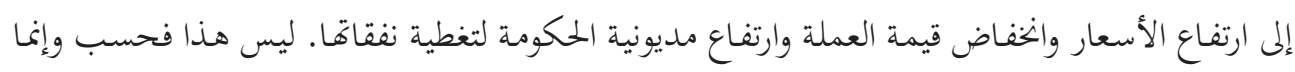

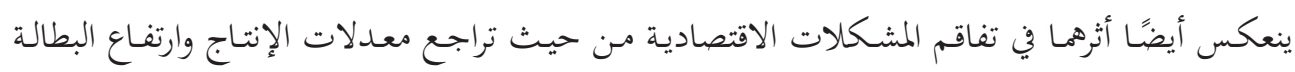

$$
\text { وزيادة معدلات الفقر وتدهور المستوى المعيشي. }
$$

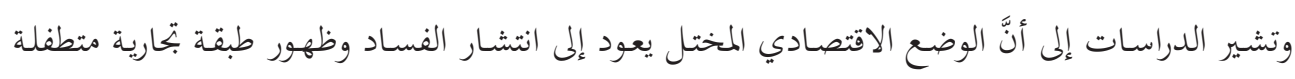

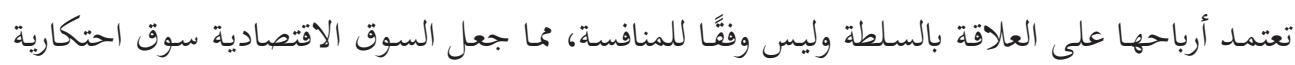

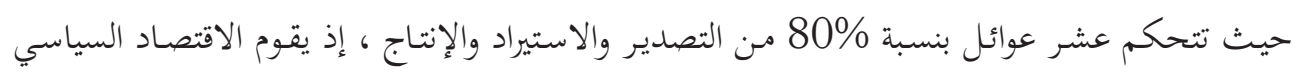

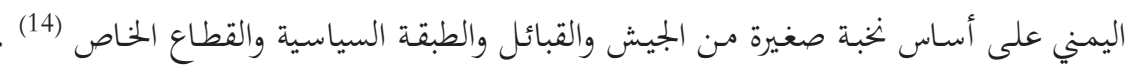
وفي ذلك أشارت مذكرة البنك الدولي بشأنَّ الجمهورية اليمنية(15) أنَّ اليمن تفتقر إلى المساواة في الفرص

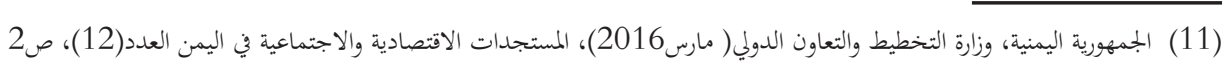

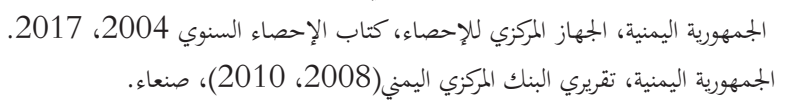

Ginny Hill، Peter Salisbury، Léonie Northedge and Jane Kinninmont، (2013)، Yemen: (14)

.Corruption، Capital Flight and Global Drivers of Conflict، A Chatham House Thomas (15) البنك الدولي، ( 20 يونيو 2016)، مؤسسة المويل الدولية، مذكرة مشاركة بشأنَّ الجمهورية اليمنية-السنة المالية2017-2018

المجلد ( 2 - - العدد (2 2 ( ) ديسمبر 2021م

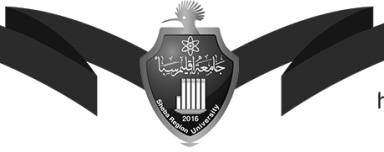


(3) د. عبلاه مدهش صالت الشجري

والعدل وسيادة القانون، وأدت هيمنة شبكات الوساطة والمحسوبية المتفشية في البلاد إلى تقويض جهود التنمية المستدامة، والحيلولة دون إدخال إصلاحات بناءة تنظر للأمور بنظرة مستقبلية، وتعميق التشوهات المتعددة التي يعاني منها الاقتصاد والتي أدت إلى نتائتج إنمائية مخيبة للآمال، إذ أدت المصالح المكتسبة

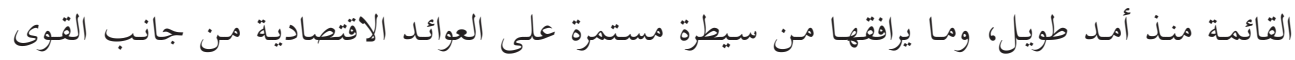
السياسية التقليدية، إلى تعقيد عملية التحول إلى نظام للإدارة العامة يتسم بالاحتواء الاجتماعي والمساواة، وأدى ذلك إلى تأكل الثقـة في الدولة ومؤسساتما .

وفي ضوء ذلك تشـير المؤشرات المؤسسية المنظمـة لعمل الاقتصـاد، أنَّ الاقتصـاد اليمتني يفتقر إلى وجـود الإطار المؤسسي المحفز للنمو الاقتصادي قبل الحرب، وهو ما ترتب عليه وجود اختلالات بنيوية في هيكل الإنتاج تثنَّل في تصدير سلعة النفط والغاز، والتي يعتمد عليها في تلبية حاجاته السلعية من الاستيرادات، وتمويل الموازنة العامة بشكل رئيس، واختلال في تحصيل الإيرادات التي شكَّلت أقل من المحلي الإجمالي. واختلالا في الإنفـاق الذي وجـه إلى الإنفـاق الجـاري على حساب الإنفاق على برامج التنمية. إن افتقار الاقتصاد إلى الإطار المؤسسي وما ترتب عليه من هيمنة شبكات الوساطات والمحسوبية والفساد وتخلف للبنية التحتية وانعدام تكافؤ الفرص وغياب الشفافية والمساءلة والتي تعد الإطار الجاذب لنشاط القطاع الخاص، فضالَ عن ظهور الاحتكار لشركات تتحكم بالاقتصـاد مقربة مـن النظام السياسي،

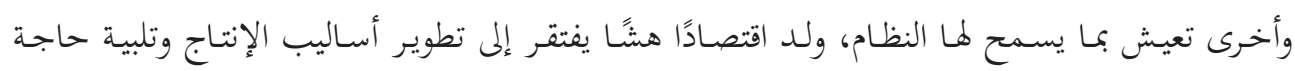
المجتمع من السلع والخدمات والقدرة على منافسة السلع الأجنبية. وجاءت الحرب لتفاقم من الاختلالات الاقتصادية الكامنة فيه، وهو مـا يتطلب إدخال إصلاحـات في الجانب المؤسسي تقود إلى تحفيز نشاط القطاع الخـاص ومعالجـة الاختلالات البنيوية في الاقتصاد. المبحث الثالث-تحليل تأثير الحرب على المتغيَّرات الاقتصادية الكلية التالية: 1 - 1 بؤشر الناتج المحلي الإجمالي: يلاحظ مـن الجدول (2) الذي يوضح المؤشرات الاقتصادية قبل الحرب، والمؤشرات الاقتصادية المتاحة بعد الحرب. وفيما يتعلق بالناتج المحلي الإجمالي بالأسعار الثابتة، يلاحظ أنَّه بلغ 26818 و 27780 و24833 مليون دولار للسنوات 2012، 2013، 2014 على التوالي وبمتوسط بلغ (26476.6) مليـون دولار. وخلال الثلاث السنوات الأولى للحرب يلاحظ أنَّ الناتج المحلي الإجمالي تراجع إلى ص.
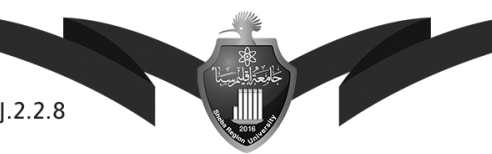

المجلد ( 2 ) - العدد ( 2 ) ديسمبر 2021م 


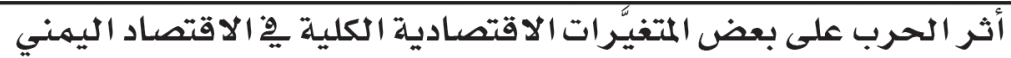

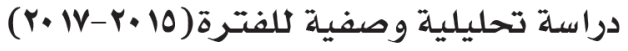

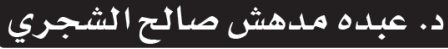

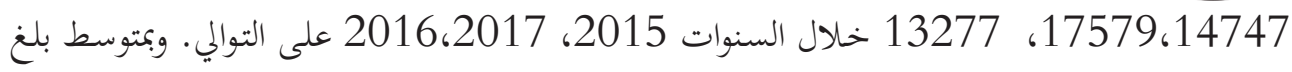

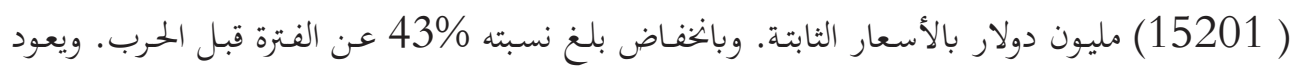

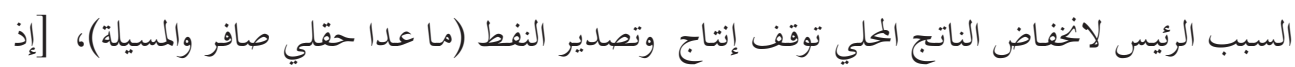

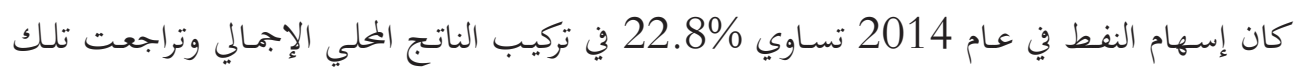

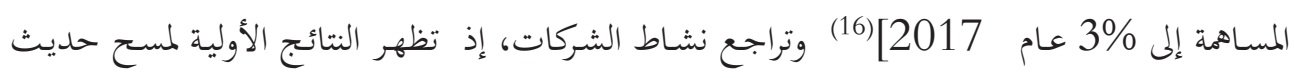

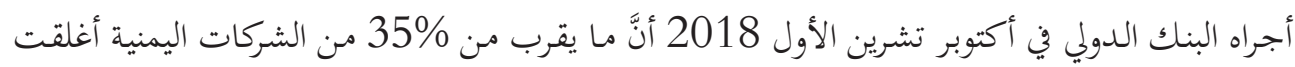

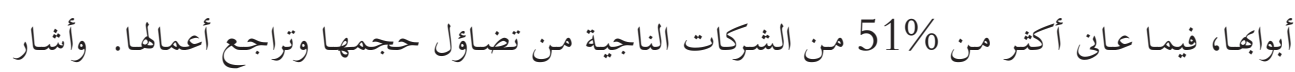

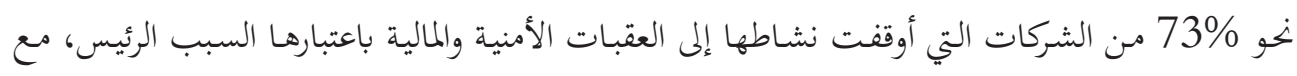

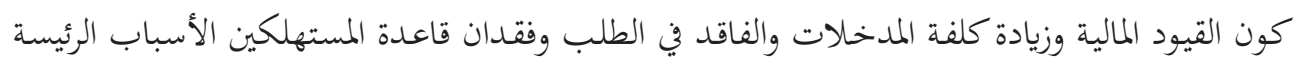

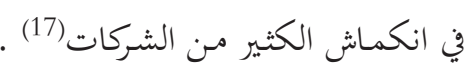

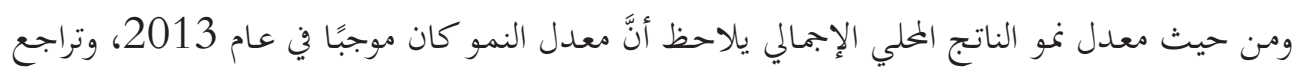

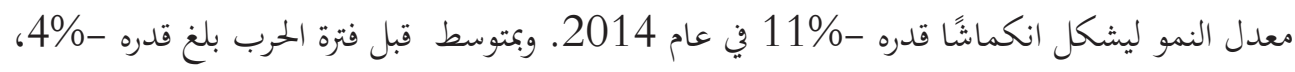

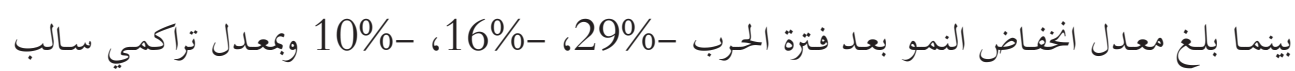

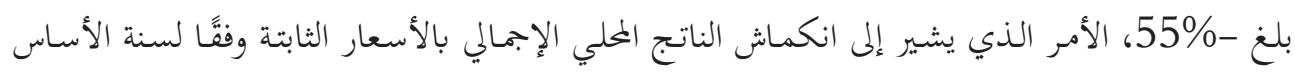

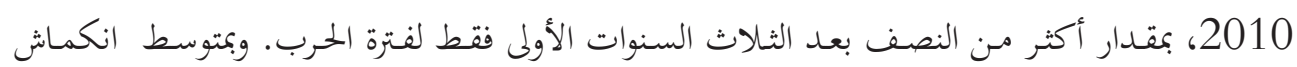

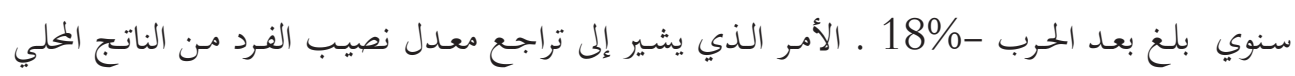

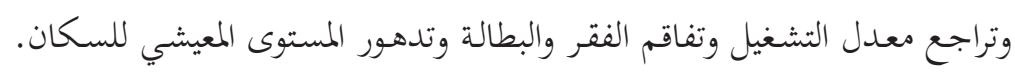

(16) (17) الجمهورية اليمنية، الجهاز المركزي للإحصاء، كتاب الإحصاء السنوي 2017 (18)

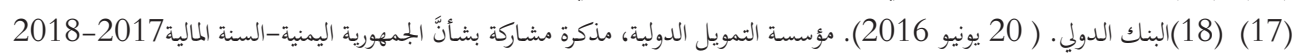

المجلد ( 2 ) - العدد ( 2 ( 2 ) ديسمبر 2021م 
أثر الحرب على بعض المتغيُرات الاقتصادية الكلية فِّاِ الاقتصاد اليهني

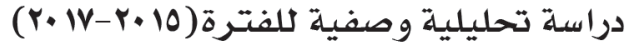

\section{د. عبلاه مدهش صالت الشجري}

جدول رقم(2) يوضح المؤشرات الاقتصادية في الجمهورية اليمنية قبل وبعد الحرب بالمليار ريال

\begin{tabular}{|c|c|c|c|c|c|c|c|c|}
\hline المتوسط & $r .1 \mathrm{~V}$ & $r .17$ & $r .10$ & المتوسط قبل & $\varepsilon 1 \cdot r$ & $r .1 T$ & $r \cdot I r$ & السنة \\
\hline $0 \varepsilon \cdot \Lambda, \varepsilon$ & $01 \wedge T, 9$ & OrI T,E & qrvo & $v \backslash 71,1$ & $v \mid r q, 0$ & $v \varepsilon \neg \wedge, 7$ & \urcorner$\wedge \vee 0, r$ & الإجمالي بسعر الملي \\
\hline $10 r \cdot 1$ & ITrVV & $1 \leqslant V \leqslant V$ & IVova & $r T \leqslant V T, T$ & $r \leqslant \Delta r T$ & YVVA. & rฯ人।V & $\begin{array}{c}\text { PDG } \\
\text { • \$ }\end{array}$ \\
\hline$\% 1 \wedge-$ & $.1, \cdot-$ & $71, .-$ & $q r, .-$ & $\varepsilon,, \cdot-$ & $11,$. & $\varepsilon \cdot$, & - & معدل النمو \\
\hline $9 \leq 1,9$ & $\wedge \backslash \varepsilon, \varepsilon$ & $7, \wedge 9 \wedge$ & $1 \cdot \pi, v$ & & rqr & rIVA & $r \leq q \cdot, \wedge$ & $\begin{array}{c}\text { إجمال الإيرادات } \\
\text { العامة }\end{array}$ \\
\hline $\mid 7 \wedge r, 1$ & Irr., q & I vor, $\varepsilon$ & $19 \times 1,9$ & rVOT,0 & rฯr & rAr $7, q$ & $r \wedge \mid r, \Lambda$ & النفقات العامة \\
\hline 1017 & IrVT,q & $17 \leq 0, r$ & $1 \wedge r q$ & OVT & r,r & ro. $\varepsilon, r$ & $r \leq T r, r$ & النفقات الجارية \\
\hline$\% 9 \leq, 0$ & $\% \varepsilon, 79$ & $\% \leqslant 9$ & \% & $\%$ \%,q人 & $\% 19$ & $\% .91$ & $\%$ \% & نسبة النفقات \\
\hline$V \varepsilon \cdot, r$ & $\varepsilon 07,0-$ & $\wedge, 乏 \circ \wedge-$ & $r, q \cdot q-$ & $1,7 r \varepsilon-$ & q,orr- & $9, \wedge \leq 7-$ & $\varepsilon, r Y r-$ & العجز في الموازنة \\
\hline$I T, V$ & $\% .9$ & $\% .71$ & $\% .71$ & \% & $\%$ & $\% .9$ & $\%$ & النسبة من الناتج \\
\hline
\end{tabular}

الجددول من عمل الباحث بالاعتماد على تقريري البنك المركزي 2013 و 2015 والاسكوى- دراسات

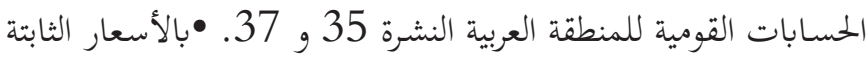
2- 2 - وضع الموازنة العامة

من المعلوم أنَّ الحكومة اعتمدات بعد الحربـ(2015-2017) في إنفاقها على الإطار العام لموازنة

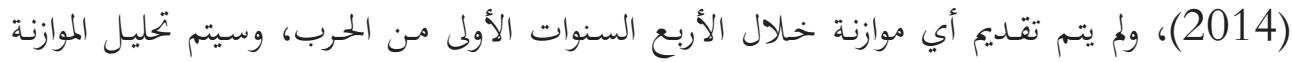

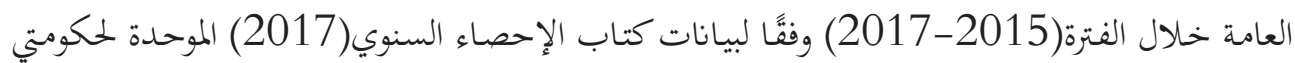
الشرعية والحوثي. ففي جانب الإيرادات للموازنة العامة ووفقا للجدول رقم (2)، يلاحظ أنَّ الإيرادات العامة الخفضت من

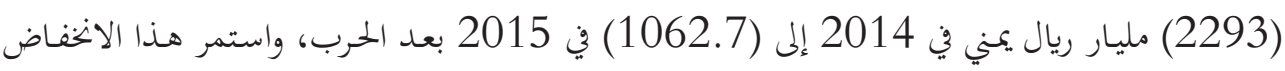




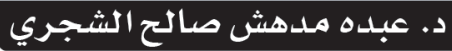

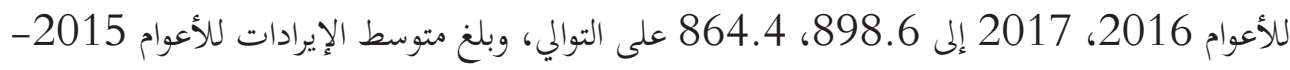

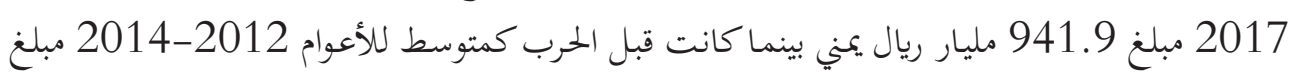

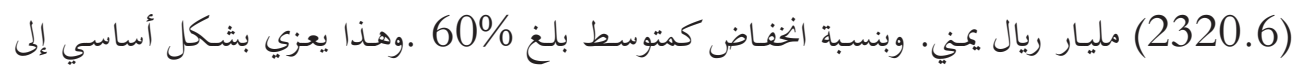
انخفاض صادرات النفط والغاز. أمَّا فيما يتعلق بجانب النفقات العامة فيلاحظ أفها الأخرى انخفضت من 2014 أنسات 2628.9 مليار ريال يمني في

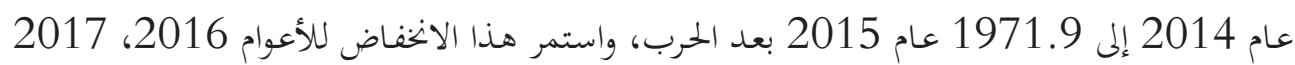

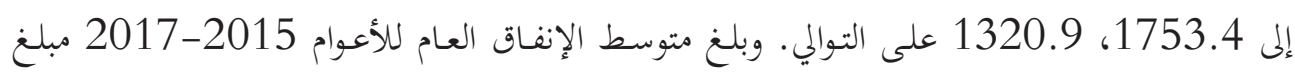

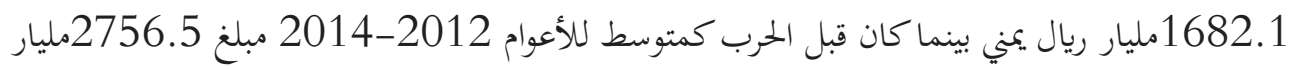

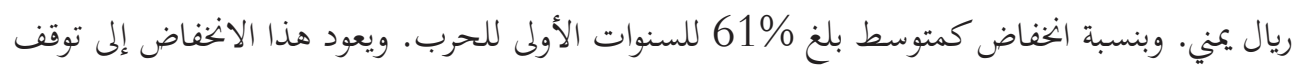

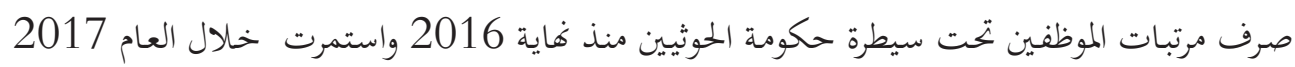
فضلاً عن توقف الإنفاق التشغيلي للخدمات وغيره من الأنشطة الاقتصادية.

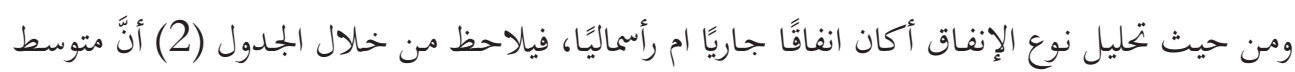
النفقات الجارية خلال الفترة 2012-2014 بلغت

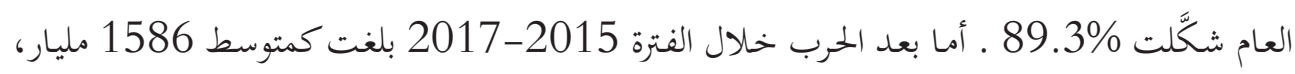

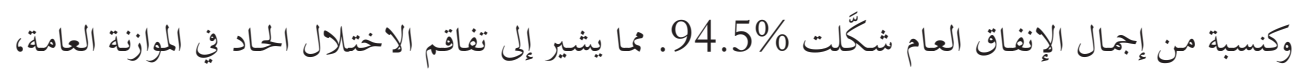

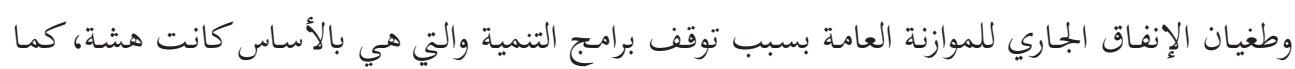

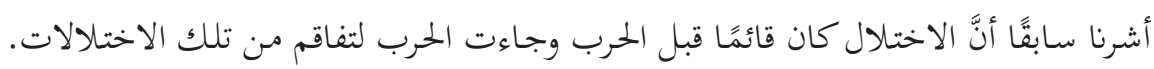

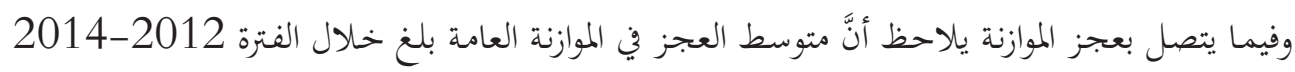

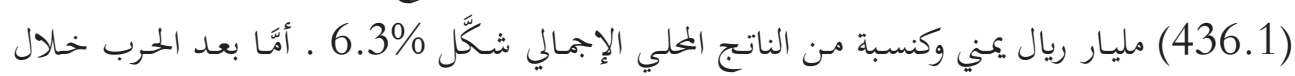

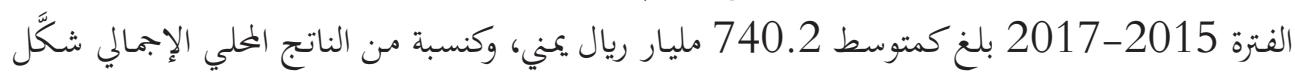

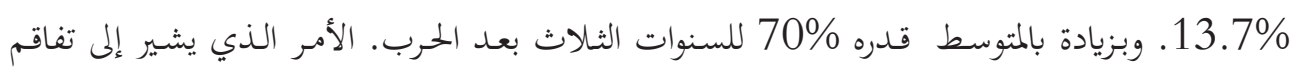

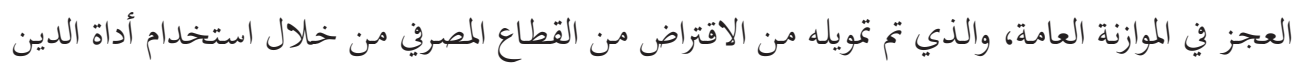

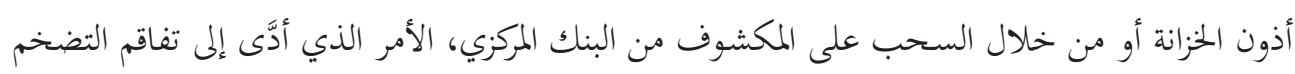

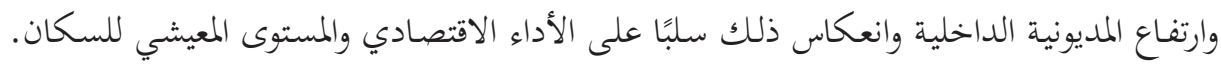

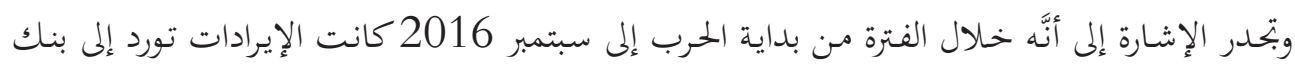

المجلد ( 2 ) - العدد ( 2 ) ديسمبر 2021م

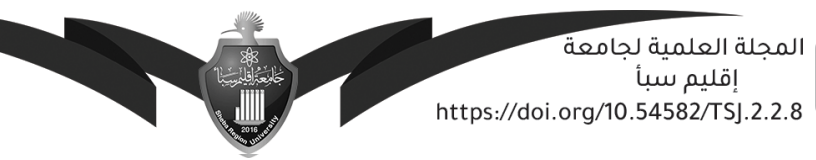


أثر الحرب على بعض المتغيَّرات الاقتصادية الكلية يِّاِ الاقتصاد اليهني

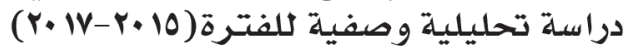

\section{د. عبلده مدهش هالج الشجري}

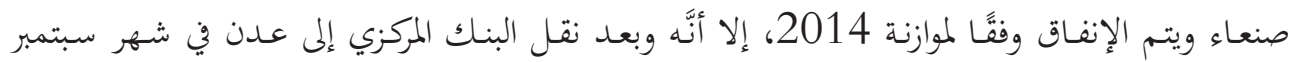
2016 تم فصل الإيرادات والنفقات بين الحكومة الشرعية وحكومة الأمر الواقع للحوثيين.

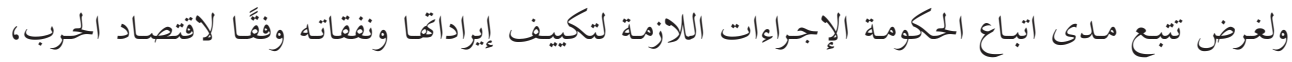

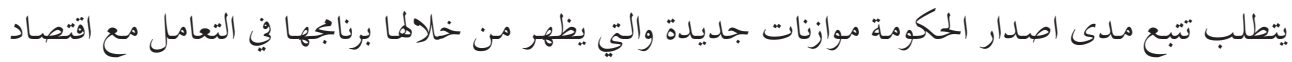
الحرب.

وفي ذلك أشارت التقارير إلى أنَّ حكومة الشرعية أصدرت القرار رقم (165) لعام 2018 بالعودة إلى

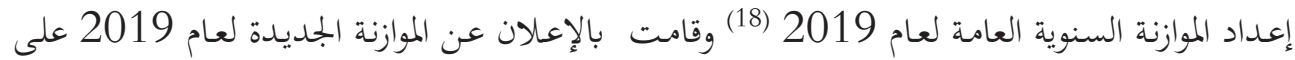

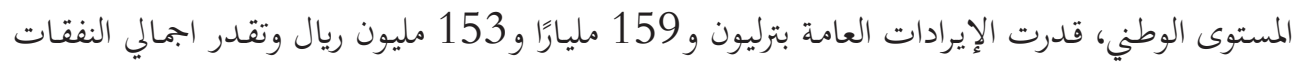

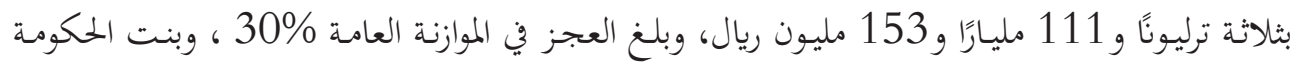

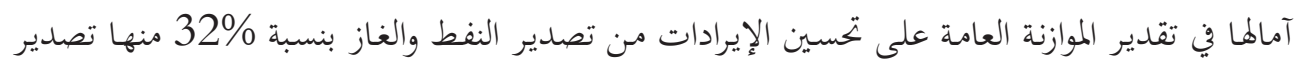

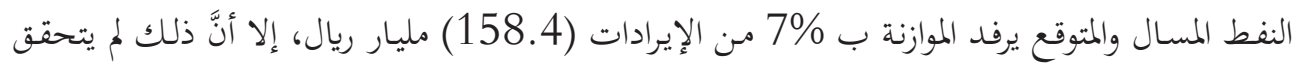

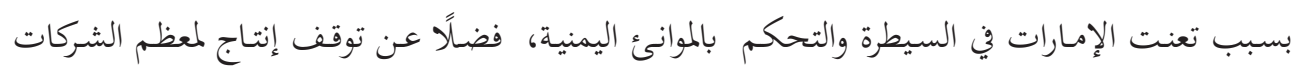

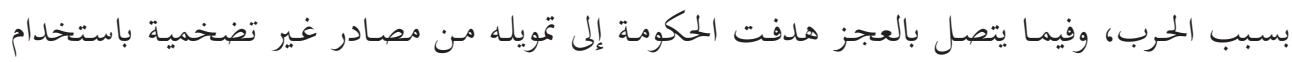

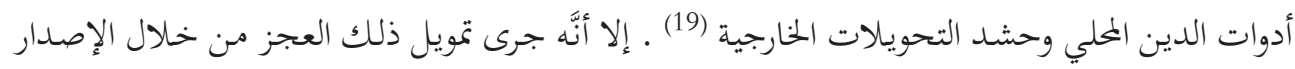
النقدي بشكل رئيسي.

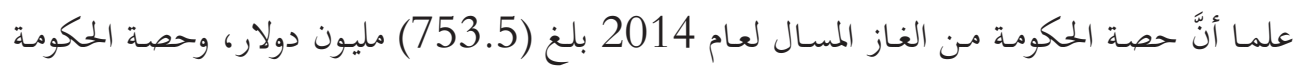
من النفط المصدر(34.3) مليون برميل (20) ، فاذ فقط افرج عن تصدير الغناز الفياز المسال وتصدير إنتاج

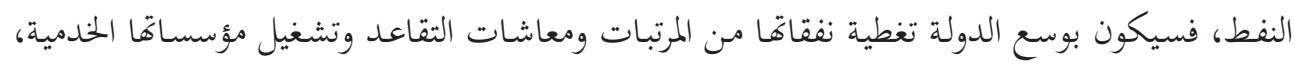

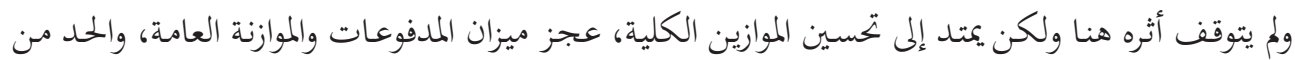

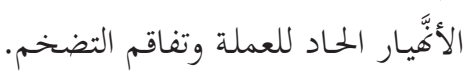

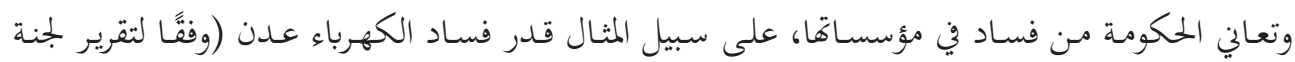

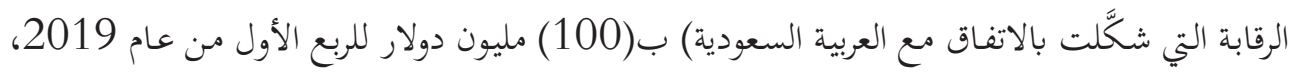

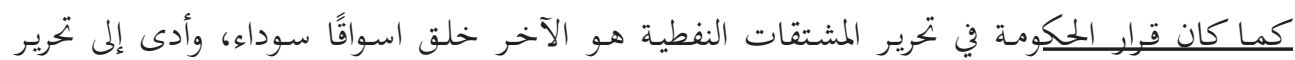

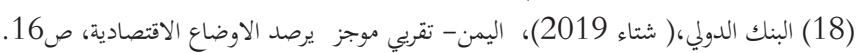

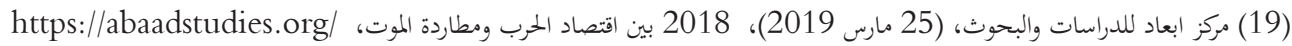
news-59798.html (20) الجمهورية اليمنية، وزارة التخطيط والتعاون الدولي ، (يونيو 2018) ، المستجدات الاقتصادية والاجتماعية في اليمن، العدد(34)، ص3.

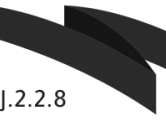




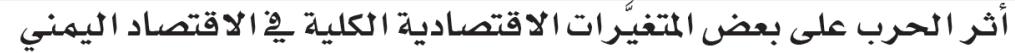

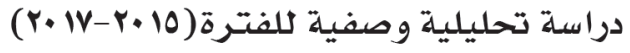

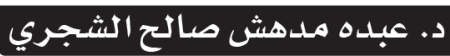

الإيرادات من الموازنة العامة إلى احتكار استيراد وتوزيع المشتقات النفطية لشركات خاصة، حيث إنبّات سلعة

النفط تتمتع بخصائص تفقد عملية المنافسة.

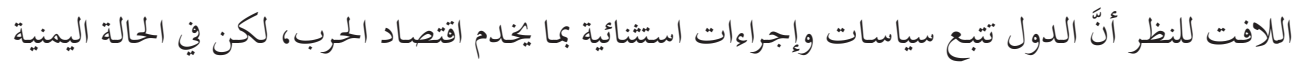

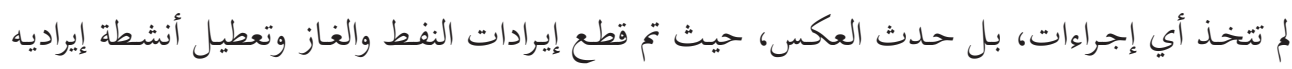
كانت تدعم الخزينة قبل الحرب.

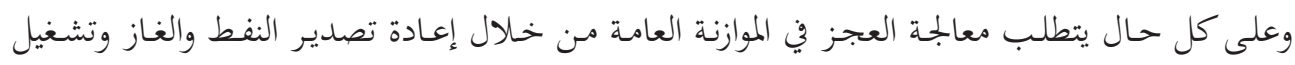

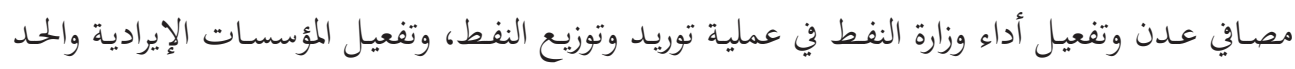

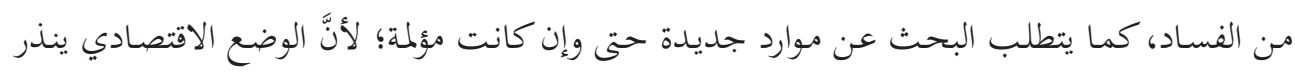

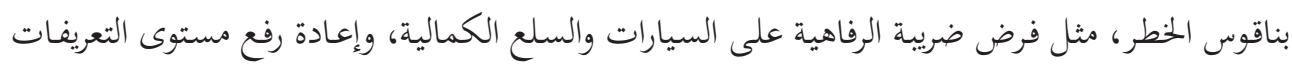

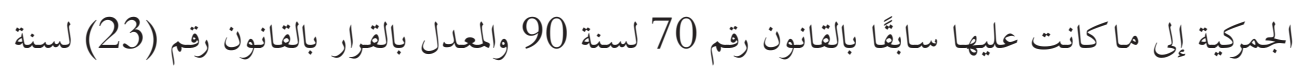
1999، ورفع مستوى الضريبة على المشتقات النفطية. وتحصيل الفاقد في الضريبة الناجم عن التهرب المبان الضريبي.

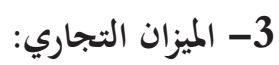

الميزان التجاري يعبر عن حركة السلع للواردات والصادرات مع العالم الخارجي، ومستوى حجم الصادرات

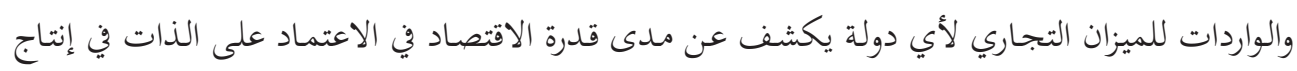

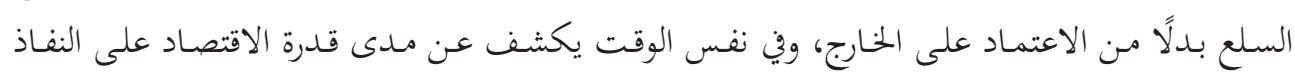
والمنافسة الخارجية من خلال التنوع في الصادرات السلعية.

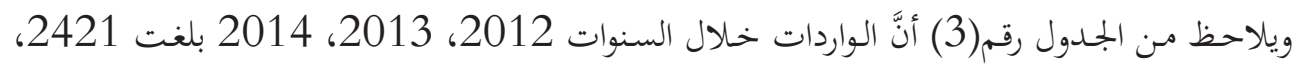

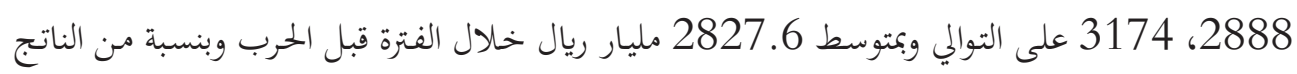

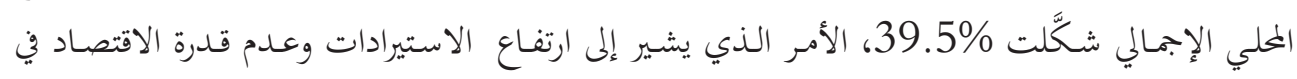

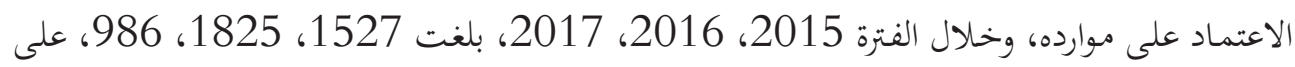

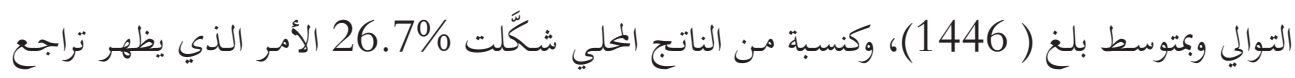

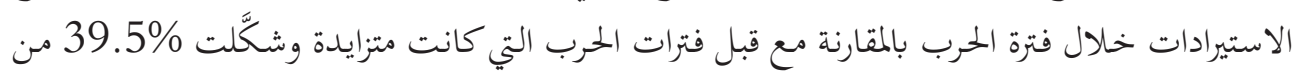

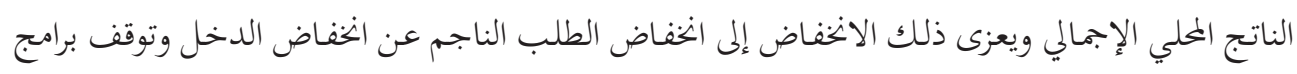

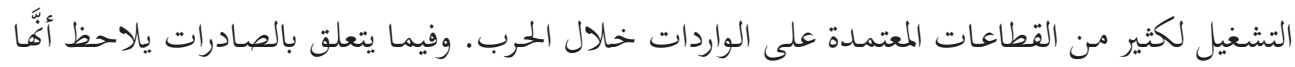


أثر الحرب على بعض المتغيَّرات الاقتصادية الكلية وِيو الاقتصاد اليمني

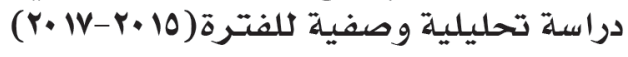

\section{د. عبلده مدهش هالج الشجري}

بلغت خلال الفترة2012-1014 كمتوسط 1499.6 مليار ريال وكنسبة من الناتج المحلي شعَّلت

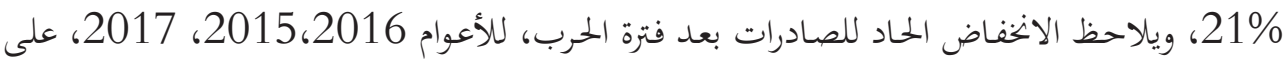

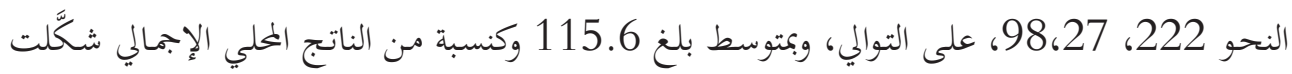

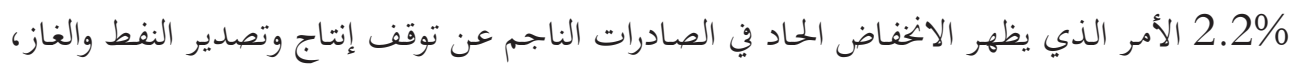

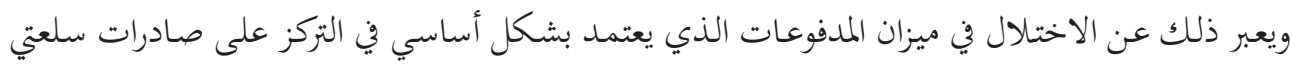

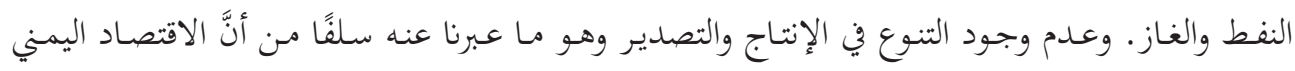
اقتصاد ريعي يعتمد في إيراداته على سلعتي النفط والغاز . وبخصوص العجز في الميزان التجاري، يلاحظ أنَّه كان متزايدًا خلال الأعوام 2012، 2013، 2013، 2014، 2013،

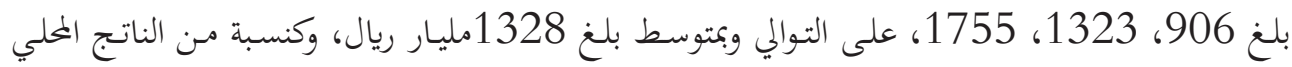

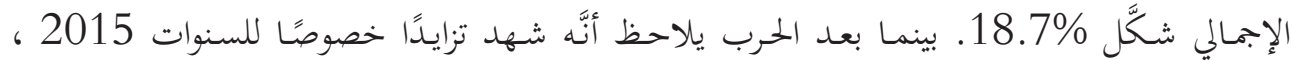

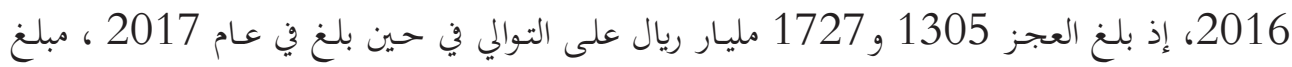

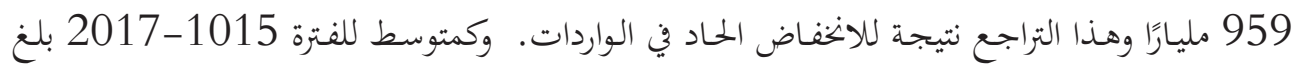

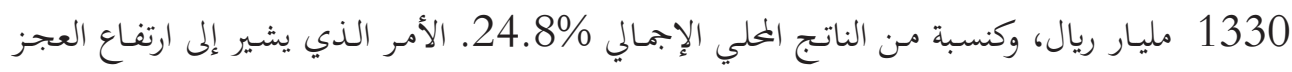

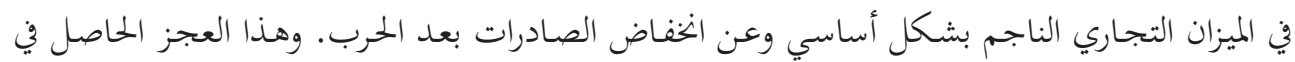

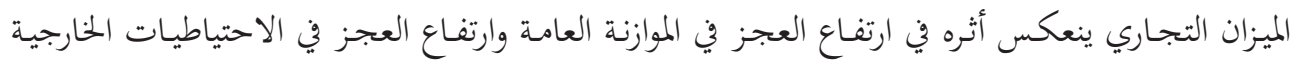

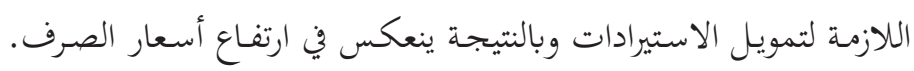
4- سعر الصرف للعملة الوطنية

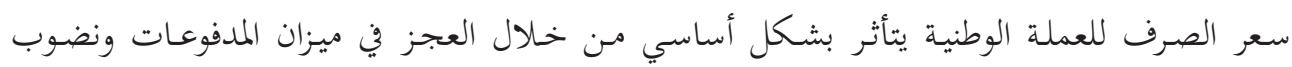

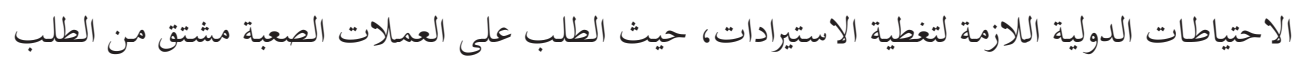

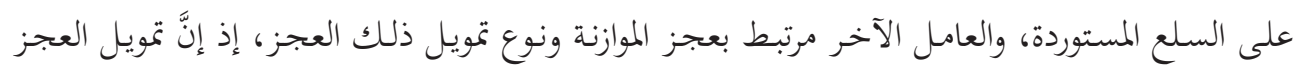

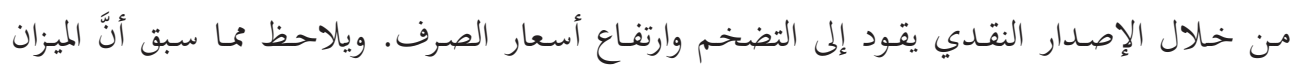

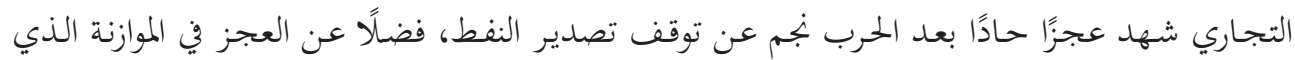

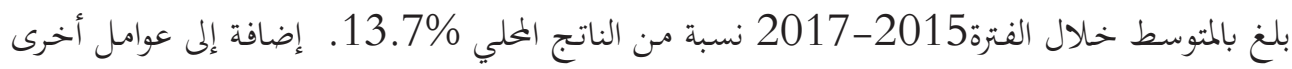
تضافرت لتنعكس على الانخفاض والتقلبات الكبيرة في سعر الصرف للعملة المحلية.

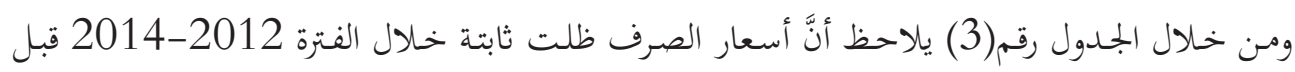

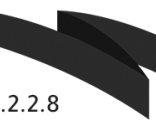




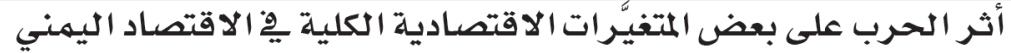

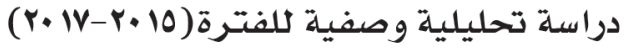

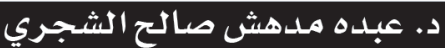

الحرب وكان المتوسط لأسعار الصرف 214.71، ويأتي ذلك نتيجة لوجود الاحتياطيات الخارجية، والتي بلغت لنفس الفترة كمتوسط (5390.7) مليون دولار . وبعد فترة الحرب يلاحظ الارتفاع المتزايد في أسعار الصرف للدولار للسنوات 2015، 2016، 2017، حيث بلغ 223.1 ، 287 ، 374 ، على التوالي، وبالمتوسط بلغت 294.7، وبزيادة عن معدل الفترة قبل الحرب بلغت 37\%. بمعنى انخفضت قيمت العملة بالمتوسط خلال الفترة 2015-2017، بمعدل سنوي قدره 37\%. والسبب يعود في ذلك إلى الانخفـاض في الاحتياطي مـن العملات الصعبـة والتي بلغت كمتوسط خلال الفـترة 2015-2017 ب 767.7 مليون دولار بالمقابل كانت قبل الحرب كمتوسط 5390.7 مليون دولار ويلاحظ تم السحب مـن الاحتياطي في السنة الأولى مـن الحـرب بمقدار 3284.4 مليون دولار. الأمـر الذي أدى إلى انخفاض الاحتياطي، وبالمقابل زيادة الضغوط في الطلب على الدولار لتمويل الاستيرادات في السوق الموازي، قاد إلى ارتفاع سعر الصرف للدولار مقابل العملة الوطنية. فضلاً عن تمويل العجز في الموازنة العامة من خلال الإصدار النقدي حيث طبعت الحكومة مبلغ ترليون و 720 مليارًا (21). علما أنَّه تم الأََّيَار في العملة الوطنية بحيث بحاوز الدولار 850 في النصف الثاني من عام 2018، إلا أنَّ الوديعة السعودية بمبلغ 2 مليار دولار في عام 2018 أدَّى إلى وقف التدهور الحاد في سعر الصرف، بحيث ظل

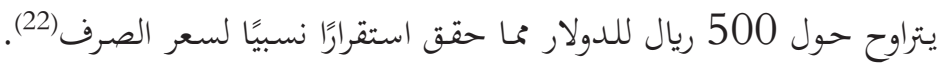
ويرتبط الأهَّيار الحاد في سعر الصرف بطبيعة الصراع بين الحكومة والانتقالي المدعوم اماراتيا فمع الانقلاب في أغسطس 2019 تفاقمت الأزمة وتفاقم معها سعر الصرف، وتزايد التفاقم مع توقع انتهاء الوديعة السعودية حيث صعد سعر الصرف ليتجاوز ال 800 ريال للدولار في عام 2020، ومع تنفيذ اتفاق الرياض وعودة الحكومة استبشر الناس خيرًا في استقرار الأوضاع، لكن ظلَّ ذلك الاستبشار مجرد وهـم، فمع عودة الحكومة ظلت مكبلة في عدم قدرها على الإشراف والرقابة وتسيير أعمال المؤسسات العامة، بسبب عـدم تنفيذ الشتق الأمني والعسكري من اتفـاق الرياض وعـاود سعر الصرف بعد أنَّ وصل إلى إلى أدنى من 500 ريال مع تزامن عودة الحكومة إلى عدن ليرتفع متجاوزًا 900 ريال للدولار في شهر فبراير 2021، محا يشير إلى أنَّ السبب في المقتـام الأول يرتبط بالاستقرار السياسي، وتمكين الحكومة مـن أداء 
(3) د. عبلده مـاهش صالح الشجري

جدول رقم(3) يوضح المؤشرات الاقتصادية بالمليارات ريال في الجمهورية اليمنية

\begin{tabular}{|c|c|c|c|c|c|c|c|c|}
\hline المتوسط بعد & $r . I V$ & $r .17$ & $r .10$ & المتوسط قبل & $r \cdot 1 \leqslant$ & $r \cdot 1 r$ & $r \cdot 1 r$ & السنوات \\
\hline $1 \leq \varepsilon 7$ & 917 & INTO & lorv & rATV,T & MV & 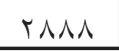 & $r \leq r \mid$ & الواردات \\
\hline$\% r \neg, \vee$ & $\% 19$ & $r \varepsilon, r$ & $r 7, V$ & $\%$ \% & $\varepsilon \varepsilon, 0$ & $r \wedge, \nu$ & $r_{0, r}$ & $\begin{array}{r}\text { كنسبة من } \\
\text { GDP }\end{array}$ \\
\hline 110,7 & rV & 91 & TMY & $1 \leq 99,7$ & $1 \leqslant 19$ & 1070 & 1010 & الصادرات \\
\hline$\%, r, r$ & $\%, 0$ & $\%$ & $\% \varepsilon$ & $\%$ & $\% 19,9$ & rI & rt & $\begin{array}{r}\text { كنسبة من } \\
\text { GDP }\end{array}$ \\
\hline 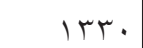 & 909 & IVTV & $1 r .0$ & |rr人| & IVoo & TrTH & $9 \cdot 7$ & العجز \\
\hline$r \leqslant, \Lambda$ & 11,0 & Tr & rt & $|\wedge, \vee|$ & ro & 11 & $\%$ & $\begin{array}{r}\text { كنسبة من } \text { GDP }\end{array}$ \\
\hline$r q \varepsilon, V$ & $r v \varepsilon$ & rAV & $r T H, 1$ & $Y|\varepsilon, V|$ & $Y \backslash \leqslant, \wedge q$ & $r \mid \leqslant, \wedge 9$ & Y $\backslash \leqslant, r_{0}$ & أسعار الصرف \\
\hline$\vee \neg V, V$ & $1 \cdot \varepsilon$ & r & $r \cdot 97, r$ & orq.,v & $\sum 770, \wedge$ & or $\leqslant \Lambda, 7$ & $71 \circ V, T$ & الاحتياطيات \\
\hline $7 \wedge \circ r, 1$ & $\Lambda \cdot r, r, \varepsilon$ & $V \cdot r V, T$ & $0 \leqslant 97, r$ & $\sum \backslash \wedge 9, \wedge$ & $\leq 771,9$ & $\sum r V \cdot, 1$ & rTrV,r & الدين العام* \\
\hline$\% r \wedge$ & 100 & IrT & 90,9 & $0 \wedge$ & $70, r$ & $\Delta V, Y$ & $0 r, 9$ & النسبة من الناتج \\
\hline$V \circ \varepsilon, q$ & $\wedge \wedge \varepsilon, q$ & $V \vee \varepsilon, Y$ & $7.0,0$ & $\varepsilon \neg \wedge, \vee$ & or $\leqslant, 1$ & $\varepsilon V Y, V$ & $\varepsilon \mid r, r$ & فائدة الدين العام \\
\hline$\% \varepsilon V, r$ & $T V,$. & $\varepsilon \varepsilon, Y$ & $r \cdot, V$ & $\mid V, r$ & $r \cdot, \varepsilon$ & $.17,9$ & $1 \leqslant, V$ & العامة \\
\hline
\end{tabular}

الجـدول مـن عمل الباحثث اعتمـادًا على كتـاب الإحصـاء السـنوي 2017، والتقريرين السنويين للبنك المركزي 2015،2013. "حتسب الدين العام للسنوات 2016، 2017 اعتمادًا على معدل نمو مدفوعـات الفوائد لتلك السنوات.

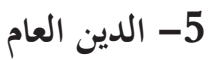
يأتي أهمية تحليل الدين العام الداخلي والخارجي في التعرف على حجم المديونية ومـدى عبئها على الاقتصاد وقدرته على تسديد اقساط المديونية. كما أنَّ تحليل عبء مدفوعات المديونية يأتي للتعرف على المدى الذي تشكله تلك النفقات من إجمال الإنفاق العام عبٍٍ على الموازنة العامة، ومدى التهام تلك 


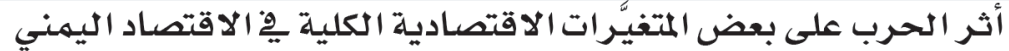

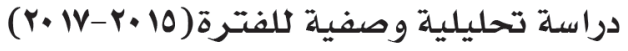

\section{د. عبله مداهش صالح الشجري}

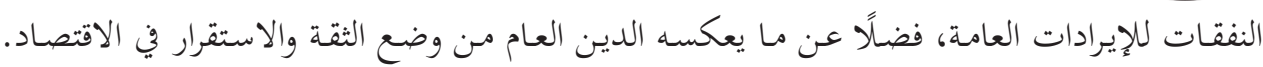

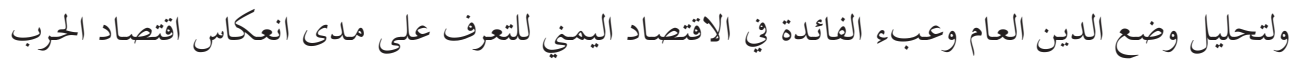

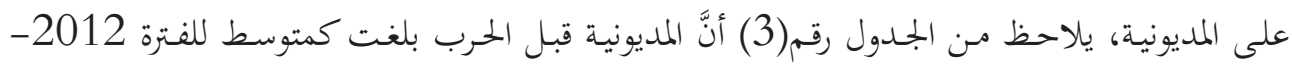

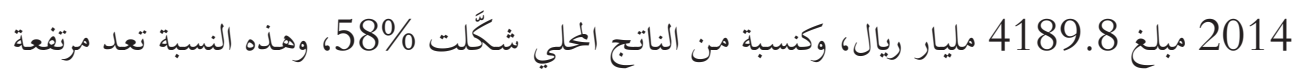

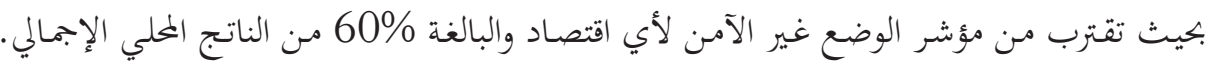

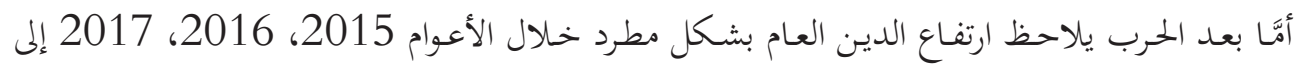

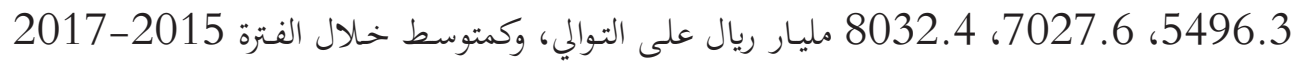

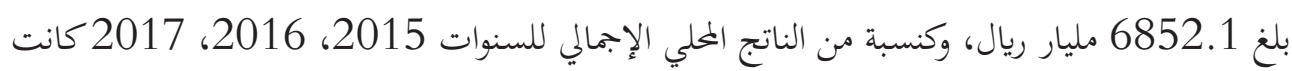

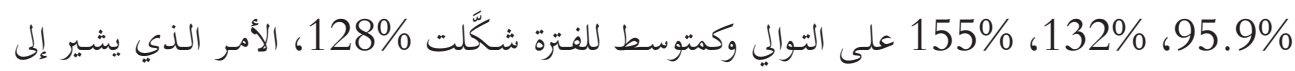

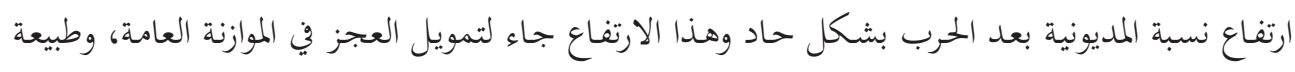

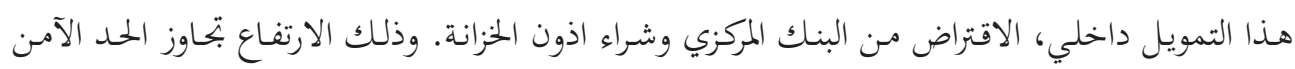
60\% في عدم قدرة الاقتصاد في الوفاء بالمديونية.

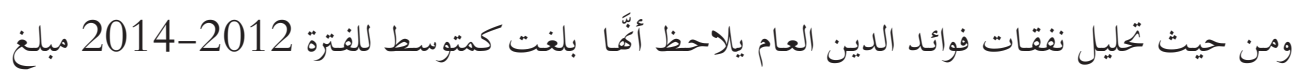

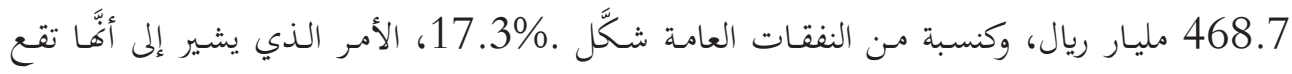

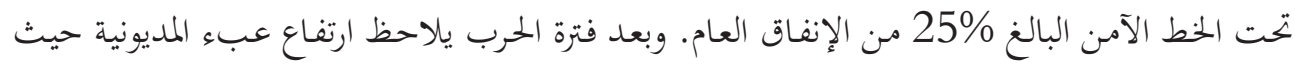

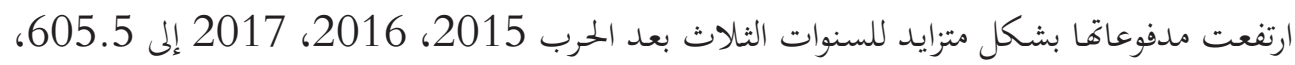

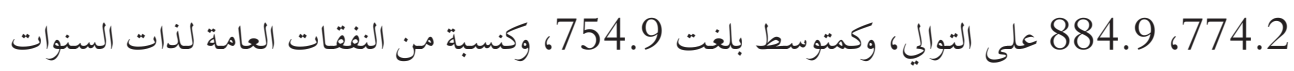

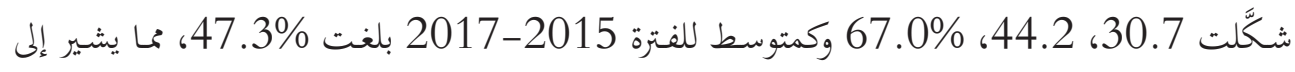

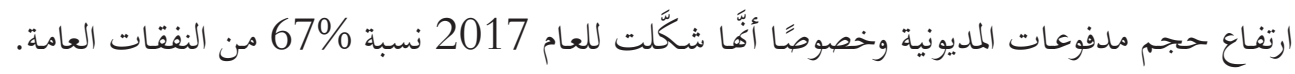

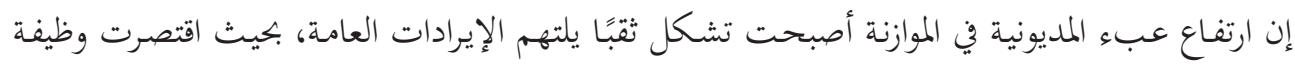

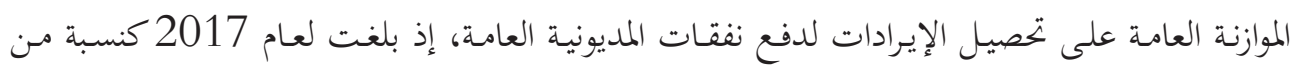

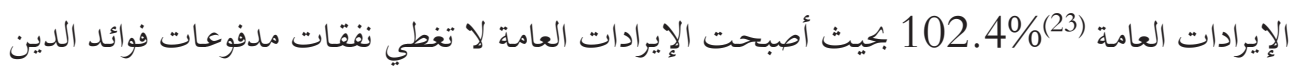

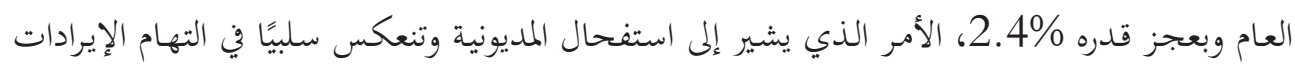

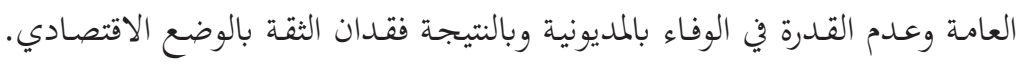

(23) الجمهورية اليمنية، الجهاز المركزي للاحصاء، كتاب الإحصاء السنوي 2017.

المجلد ( 2 ) - العدد ( 2 ( 2 ) ديسمبر 2021م

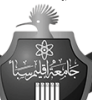

المجلة العلمية لجامعة 
(7)

د. عبلده مدهش هالج الشجري

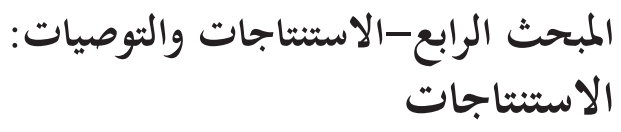

1-عانى الاقتصاد اليمني قبل الحرب من اختلال بنيوي في هيكل الإنتاج تمثل في عدم تنوع الإنتاج وعدم

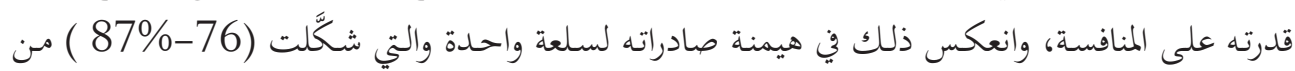
إجمال الصادرات، ويعتمد في تلبية حاجاته السلعية على الاستيرادات والتي شكَّلت 34\% من GDP، واختلالٍ في تحصيل الإيرادات بحيث شكَّل تحصيل الضرائب أقل مـ 9\% 9\% مـن الناتج المحلي الإجمالي. واختلالٍ في الإنفاق الذي وجه إلى الإنفاق الجاري على حساب الإنفاق على برامج التنمية. 2-إن الافتقار إلى الإطار المؤسسي ومـا ترتب عليه مـ هيمنـة شبكات الوساطات والمسسوبية والفساد وتخلف للبنية التحتية وانعدام تكافؤ الفرص وغياب الشفافية والمساءلة والتي تعد الإطار الجاذب لنشاط القطاع الخـاص، ولد اقتصادًا هشًُا يفتقـر إلى تطوير أساليب الإنتاج وتلبية حاجـة المجتمع مـن السـع والحندمات والقـدرة على منافسـة السـلع الأجنبية. وجـاءت الحرب لتفاقم مـن الاختـلالات الاقتصادية الكامنة فيه، وهو ما يتطلب إدخال إصلاحات في الجانب المؤسسي تقود إلى تحفيز نشاط القطاع الخناص ولماص ومعالجـة الاختـلالات البنيوية في الاقتصـاد.

3-انكماش الناتج المحلي الإجمالي بمعدل تراكمي خهلال السنوات الثـلاث الأولى للحرب بلغ 55\%. وهـذه النتيجة تحقق فرضيـة البحثث الخاصة بأثر الحـرب على الناتج المحلي الإجمالي.

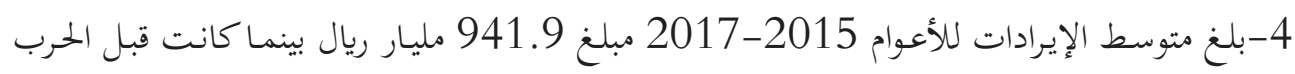
كمتوسط للأعوام 2012-2014 مبلغ 2320.6 مليار ريال. وبنسبة انخفـاض سنوي كمتوسط بلغ 60\% .وهذا يعزى بشكل أساسي إلى انخفاض صادرات النفط والغاز.

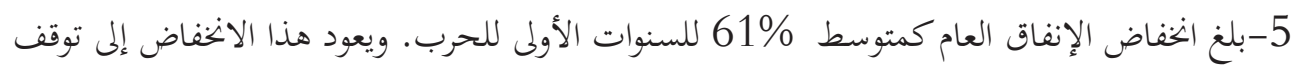
صرف مرتبات الموظفين تحت سيطرت حكومة الحوثيين منذ فاية 2016 واستمرت خلال العام 2017

فضاً عن توقف الإنفاق على تشغيل الخدمات العامة وغيرها من الأنشطة الاقتصادية والاجتماعية. 6-تفاقم اختلال الإنفاق العام بحيث أصبح الإنفاق الجاري بالمتوسط بعد الحرب قبل الحرب يشكل نسبة 89.3\% والنسبة المتبقيـة المخصص للنفقـات الرأسمالية، حيث اقتصر الإنفاق العام على الرواتب والأجور بشكل أساسي، وتوقف برامج التنمية. 7-بلغ عجز الموازنة العامة خلال الفترة ( 2012-2014) 436.1مليار ريال وكنسبة من الناتج المحلي 


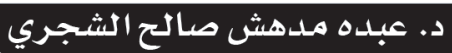

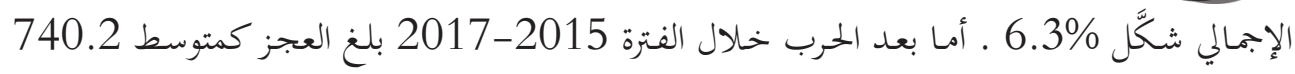

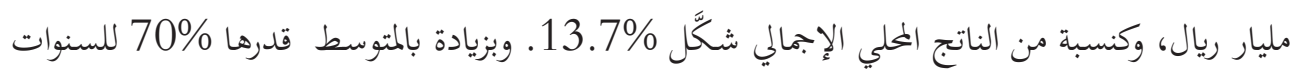

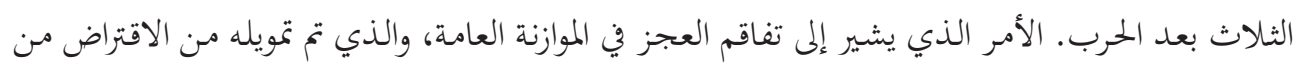

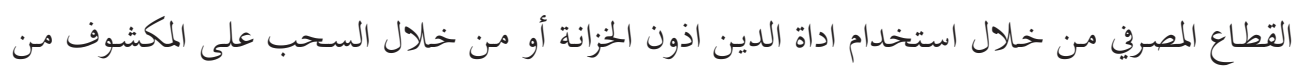

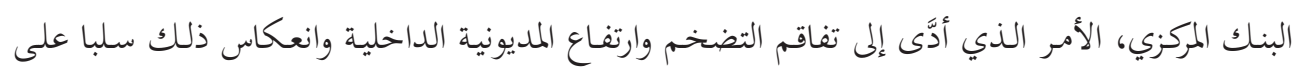

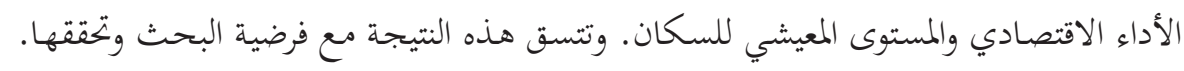

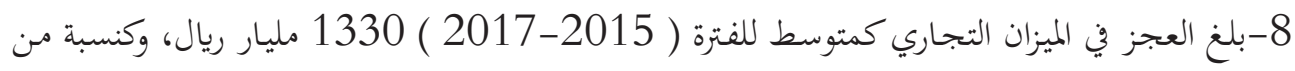

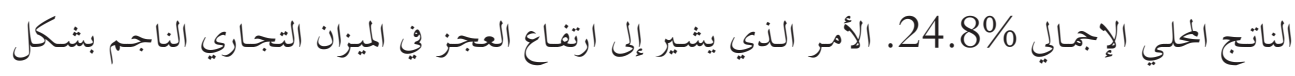

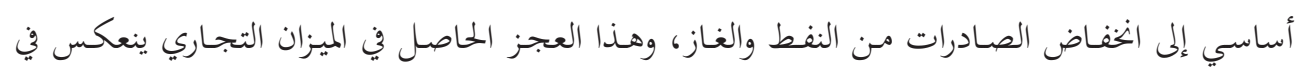

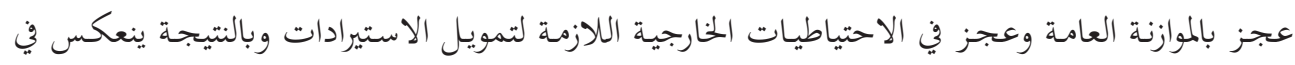

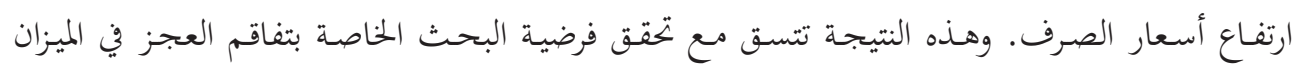
التجـاري.

9-انخفضت قيمة العملة بالمتوسط خلال الفترة 2015-2017، بمعدل سنوي 37\%. والسبب يعود

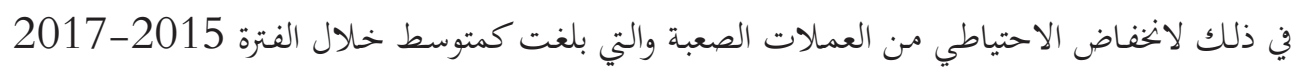

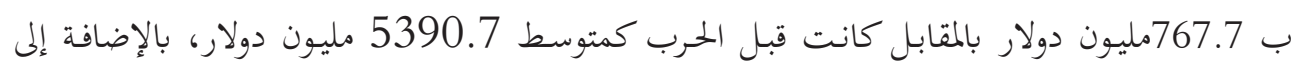

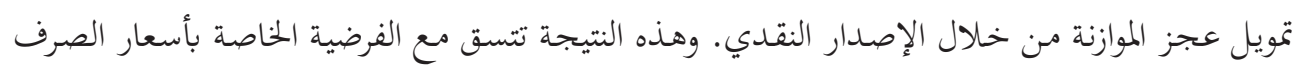

وتحققها.

10-ارتفعت نسبة المديونية بعد الحرب بشكل حاد، حيث بلغت كمتوسط للفترة (2015-2017) بحيث شعَّلت 128\%، 10، وهذا الارتفاع جاء لتمويل العجز في الموازنة العامـة، وطبيعة هذا التمويل

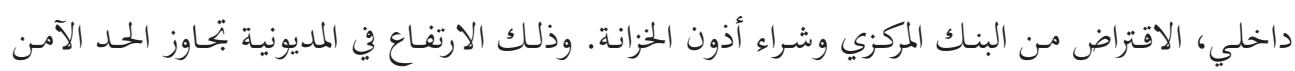

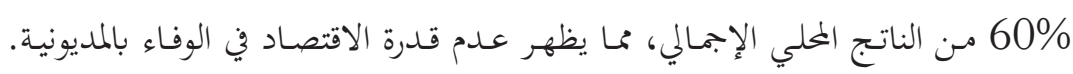

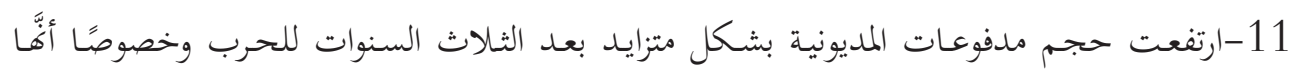

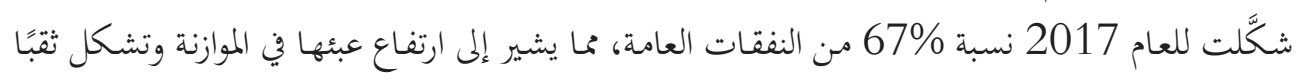

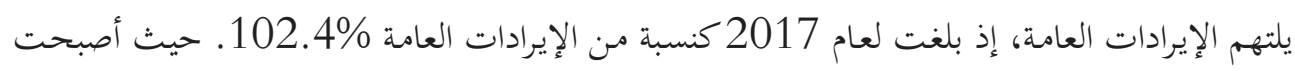

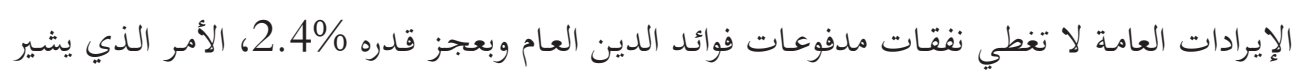


إلى استفحال المديونية وأصبحت تدق ناقوس الخططر في عدم القدرة في الوفاء بالمديونية وبالنتيجة فقدان الثقة بالوضع الاقتصادي. وهذه النتيجة تحقق فرضية البحث الخاصة بأثر الحرب على المديونية. 12- تتبع الدول سياسات وإجراءات استثنائية بما يخدم اقتصاد الحرب، لكن في الحالة اليمنية لم تتخذ أي إجراءات، بـل حـدث العكس، حيث تم قطع إيرادات النفط والغـاز وتعطيل أنشطة إيراديـة كانت تدعم الخزينة قبل الحرب. وبتحر الإشارة إلى أنَّ معظم نتائج البحث تتسق مع الدراسات السابقة، من حيث انعكاس الحروب على لى الاوضاع الاقتصادية والاجتماعية، وطبيعة الاختلافات تعود إلى اختلافات في طبيعة الصراعات الداخلية وطبيعة تغذيتها الخارجية. 


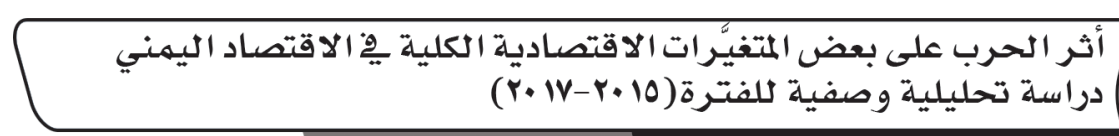

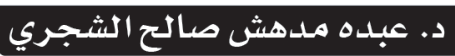

التوصيات

تتصل التوصيات بالمعالجات للمرحلة الآنية في ظل اقتصاد الحرب، وذلك من خلال البحث عن الموارد

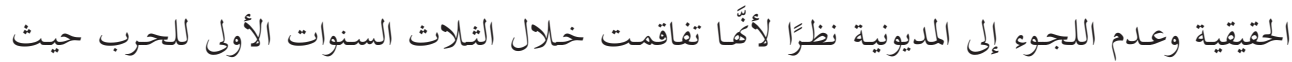
أصبحت تمدد وضع الاقتصاد وعبؤها غير قادر الاقتصاد على تحملها. وتقتصر المعالجات بشكل أساسي على العجز في الميزان التجاري والعجز في الموازنة العامة، لان العجز أو الاختلال بهاذين الميزانين ينعكس العس وله أثرهما على معالجة الاختلال في بقية المتغيَّرات الكلية، وهي سعر الصرف والتضخم والمديونية والناتج المحلي الإجمالي، ومن ثم المستوى المعيشي للسكان، وتتمثل بما يلي: 1-يتطلب إعـادة تصدير النفط والغاز، والعمل على رفع مستوى الإنتاج للحقول النفطية، للدولة والشركات الأجنبية وتوفير الشروط والظروف اللازمة لتحقيق ذلك. 2-تشغيل مصافي عدن، وتفعيل المؤسسات الإيرادية، كما يتطلب البحث عن موارد جديدة مثل فرض

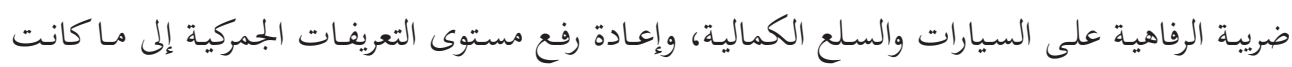
عليها سابقًا بالقرار رقم(23) لسنة 1999، ورفع كفاءة مصلحة الضرائب لتحصيل الفاقد في الضريبة الناجم عن التهرب الضريبي.

3- العمل على تحقيق برنامج تقشف للإنفاق العام وترشيده ورفع كفاءته.

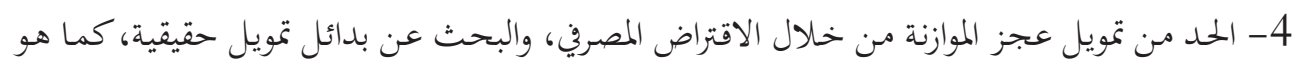
الحال رفع الضرائب على الجمارك. 5-تفعيل أداء جهاز الرقابة والمحاسبة للحد من الفساد في مؤسسات الدولة، بغية تفعيل الإيرادات العامة، وتنميتها بـلًا من الدين العام الذي أضحى خطرًا يهدد كيان الاقتصاد وغير قابل للعلاج في المستقبل. 6- تفعيل أداء وزارة النفط للقيام بعملية الاستيراد والتوزيع للمشتقات النفطية، والحد من عملية احتكار استيراد المشتقات النفطية، وتوفير الإيرادات لخزانة الدولة بدلًا عن ذهابها إلى جيوب المحتكرين لاستيراد وتوزيع المشتقات النفطية.

7- تفعيل أداء مؤسسات الموانئ وخصوصًا ميناء عدن، لتفعيل نشاطها وتنمية إيراداتا.

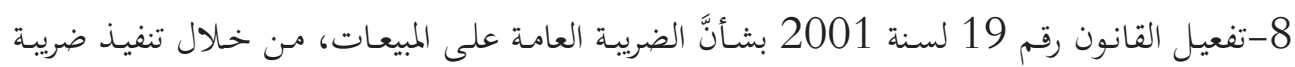

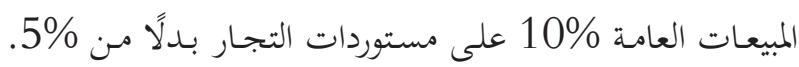
9-رفع سعر المشتقات النفطية في مأرب بشكل متوازن وبما يحـد مـن التهريب وخلق الأسواق السوداء،

المجلد ( 2 ) - العدد ( 2 ( 2 ) ديسمبر 2021م

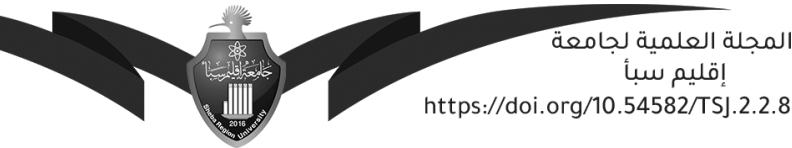




$$
\begin{aligned}
& \text { أثر الحرب على بعض المتغيَر ات الاقتصادية الكلية بِّإلاقتصاد اليهني }
\end{aligned}
$$

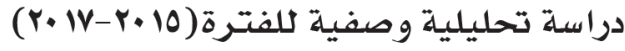

\section{د. عبده مدهش صالح الشجري}

$$
\text { ورفد الموازنة المحلية والعامة بالإيرادات. }
$$

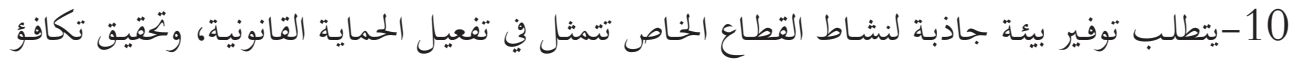
الفرص والشفافية والمساءلة والمحاسبة وتبسيط الإجراءات لنشاطئة لنشاط الأعمال.

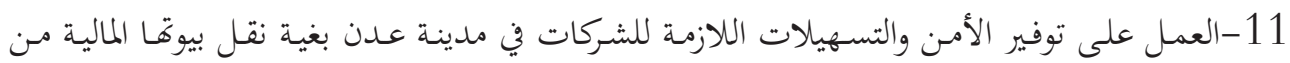
العاصمة صنعاء إلى العاصمة التجارية عـدن.

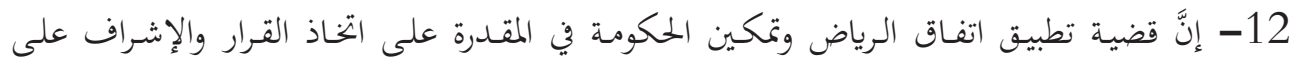

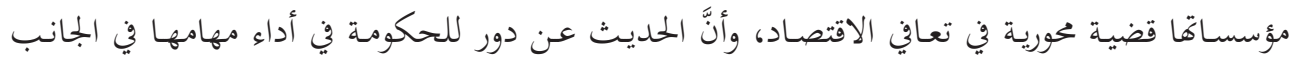

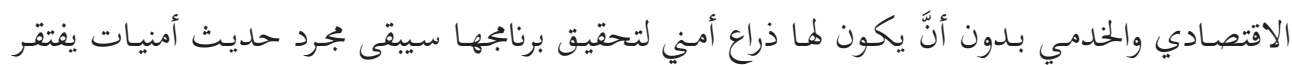
إلم إلى الموضوعية. 
1-الحميري، محمد أحمد، (23. يناير 2018)، اقتصاد الحرب في اليمن :التدابير الاقتصادية لجماعة

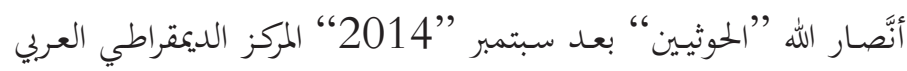
https//:democraticac.de?/p51726=

2-خليل، شذا،( 11 اكتوبر 2018) الحروب الاقتصادية سلاح فتاك في اختلال موازين الدول، مركز الروابط للبحوث والدراسات الاستراتيجية، لتداك،

https://rawabetcenter.com/archives/75567

3-مصطفى نصر، مركز الدراسات والإعلام اليمني (2018)، تقرير مؤشرات الاقتصاد في اليمن

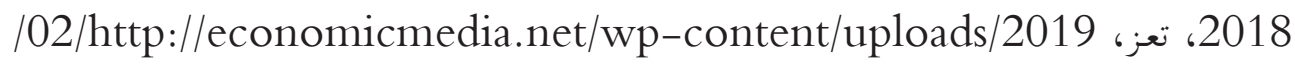

AREconomicReport2018.pdf

$$
\text { 4-(غير معروف الاسم)، اقتصاد الحرب، المعرفة، }
$$

https//:www.marefa.org/

مركز أبعاد للدراسات والبحوث، (25 مـارس 2019)، 2018 بين اقتصاد الحرب ومطاردة الموت، https//:abaadstudies.org/news.59798-html

ب- التقارير والدراسات والنشرات الصادرة عن المؤسسات الدولية والإقليمية

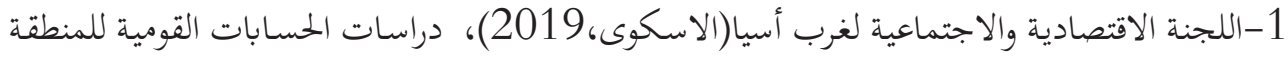

$$
\text { العربية النشرة (37)، الأمم المتحدة، نيويورك. }
$$

2-البنك الدولي، ( 20 يونيو 2016)، مؤسسة التمويل الدولية، مذكرة مشاركة بشأنَّ الجمهورية

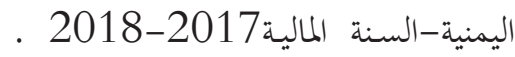

3-البنك الدولي،( شتاء 2019)، اليمن - تقرير موجز يرصد الاوضاع الاقتصادية.

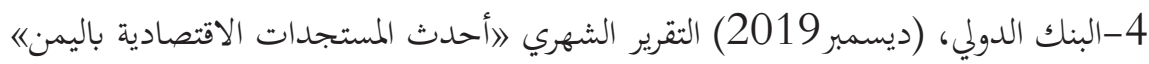

5-البنك الدولي، تقارير نشاط الأعمال على الرابط

file///:C/:Users/win10/AppData/Local/Temp/DB10-ArabWorld-

المجلد ( 2 ) - العدد (2 2 ) ديسمبر 2021م 


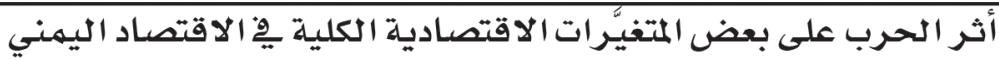

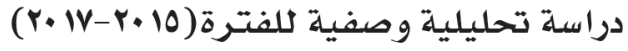

\section{د. عبلاه مدهش صالج الشجري}

Arabic.pdf

6-تقارير منظمة الشفافية العالمية على الموقع 7ww.transparency.org/files 7-التقارير السنوية تصدر عن المنتدى الاقتصادي العالمي للتنافسية على الموقع https//:www.weforum.org/reports/the-global-competitiveness 8-الحديدي، دانة، (17 أكتوبر 2016 )، س و ج كل ما تريد معرفته عن اقتصاد الحرب، صحيفة اليوم السابع المصرية https//:www.youm7.com/story2926016//17/10/2016/

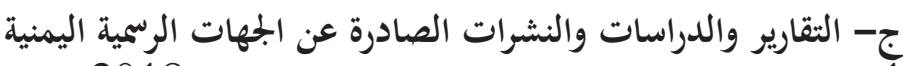

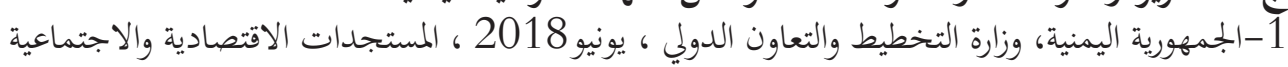

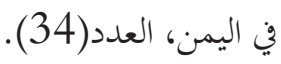
2-الجمهورية اليمنية، وزارة التخطيط والتعاون الدولي( سبتمبر 2020)، المستجدات الاقتصادية

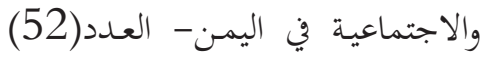
3-الجمهورية اليمنية، وزارة التخطيط والتعاون الدولي،مارسية 2016، المستجدات الاقتصادية والاجتماعية، العدد(12). (12). 4-الجمهورية اليمنية، الجهاز المركزي للإحصاء، كتاب الإحصاء السنوي 2004، صنعاء. 5-الجمهورية اليمنية، الجهاز المركزي للإحصاء، كتاب الإحصاء السنوي لإحكاء، كتاب الإحصاء السنوي 2017، صنعاء.

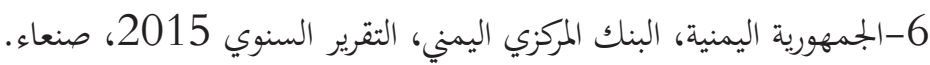

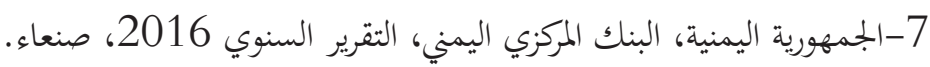

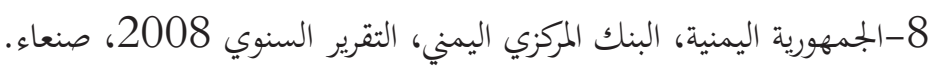

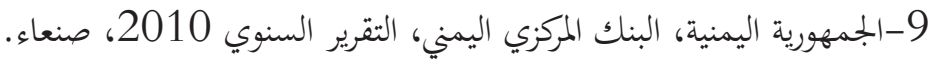
ثانيا:المصادر باللغة الانجليزية

1- Bruno Schönfelder(2005) THE IMPACT OF THE WAR 1991 - 1995 ON THE CROATIAN ECONOMY. A CONTRIBUTION TO THE ANALYSIS OF WAR ECONOMIES، Economic Annals no 166، July 2005 - September 2005. 
2-Clifford F. Thies and Christopher F. Baum.(winter 2020)، The Effect of

War on Economic Growth، Cato Journal، Vol. 40، No. 1. Cato Institute. DOI:10.36009/CJ40.1.10

2-Ginny Hill، Peter Salisbury، Léonie Northedge and Jane Kinninmont، (2013)، Yemen: Corruption، Capital Flight and Global Drivers of Conflict، A Chatham House Thomas.

3- Julian Paul Ehmer، On the Economic Consequences of Civil Conflict The Case of Sierra Leone، International Development Studies، BIN 880904-218090

4- Imai. Kosuke and Weinstein. Jeremy (June 2000)، Measuring the Economic Impact of Civil War، CID Working Paper No. 51 June 2000، Harvard university.

5-Plumper and Eric Neumayer، (Summer 2006) ، the Unequal Burden of War: The Effect of Armed Conflict on the Gender Gap in Life Expectancy، International Organization 60، pp. 723754-.

6- Serneels. Pieter and Verpoorten. Marijke (2012). The Impact of Armed Conflict on Economic Performance: Evidence from Rwanda، Journal of Conflict Resolution 201X، Vol XX(X) 138-.

7- Peace Research Institution Oslo (2012)، Development consequents of armed conflict، World Development Vol. 40، No. 9، pp. 1713-1722، 2012. 8-Institute for Economics \& Peace (IEP)، ECONOMIC CONSEQUENCES OF WAR on the U.S. ECONOMY، New York. 